\title{
Organ-specific Adverse Events of Immune Checkpoint Inhibitor Therapy, with Special Reference to Endocrinopathies
}

\author{
Annu Susan George, ${ }^{1}$ Cornelius J Fernandez, ${ }^{2}$ Dilip Eapen ${ }^{2}$ and Joseph M Pappachan ${ }^{3,4,5}$ \\ 1. Department of Medical Oncology, Lakeshore Hospital, Cochin, Kerala, India; 2. Department of Endocrinology, Pilgrim Hospital, United Lincolnshire \\ Hospitals NHS Trust, Boston, UK; 3. Department of Endocrinology \& Metabolism, Lancashire Teaching Hospitals NHS Trust, Preston, UK; \\ 4. Manchester Metropolitan University, Manchester, UK; 5. The University of Manchester, Manchester, UK
}

DOI: https://doi.org/10.17925/EE.2021.17.1.21

vario mions mmune checkpoint inhibitors are potent and promising immunotherapeutic agents that are increasingly used for the management of various types of advanced cancers. The widespread approval of this group of drugs simultaneously revealed immune-related adverse events as unique side-effects. Endocrinopathies are one of the most common immune-related adverse events. The precise pathogenic mechanisms for these endocrinopathies are still unclear. Though few of the endocrinopathies are reversible, calling for only symptom control, most are irreversible, requiring multiple long-term hormone replacement therapies. However, in contrast to other organ-specific immune-related adverse events, patients with endocrinopathies can continue their immune checkpoint therapy, provided the hormone replacement therapy is adequate and the symptoms are controlled. Though patients who have developed immune-related adverse events demonstrate superior antitumor activity and overall survival, due to the high morbidity associated with the immune-related adverse events, researchers are trying to uncouple the antitumour activity associated with immune checkpoint inhibitor therapy from the immune-related adverse events, to preserve antitumour activity without adverse events.

\section{Keywords}

Immune checkpoint inhibitors, endocrinopathies, immune-related adverse events, hypophysitis, hypothyroidism, hyperthyroidism, adrenal insufficiency, autoimmune diabetes

Disclosure: Annu Susan George, Cornelius J Fernandez, Dilip Eapen and Joseph M Pappachan have no financial or non-financial relationships or activities to declare in relation to this article. Review process: Double-blind peer review.

Compliance with ethics: This study involves a review of the literature and did not involve any studies with human or animal subjects performed by any of the authors.

Authorship: The named authors meet the International Committee of Medical Journal Editors (ICMJE) criteria for authorship of this manuscript, take responsibility for the integrity of the work as a whole, and have given final approval for the version to be published. Annu Susan George and Cornelius J Fernandez contributed equally to this paper and share the first authorship.

Access: This article is freely accessible at

touchENDOCRINOLOGY.com. @ Touch Medical Media 2021

Received: 7 December 2020

Accepted: 9 February 2021

Published online: 7 April 2021

Citation: touchREVIEWS in Endocrinology.

2021;17(1):21-32

Corresponding author: Joseph M Pappachan, Department of Endocrinology \& Metabolism, Royal Preston Hospital, Lancashire Teaching Hospitals NHS Foundation Trust, Preston, Lancashire, UK PR2 9HT. E: drpappachan@yahoo.co.in

https://orcid.org/0000-0003-0886-5255

Support: No funding was received in

the publication of this article.
Immune checkpoints are small molecules that are present on the cell surface of T lymphocytes to regulate the immune response. While some of these molecules enhance the stimulatory signals, others boost the inhibitory signals to blunt the activity of T lymphocytes (intrinsic down-regulators of immunity). ${ }^{1}$ The stimulatory checkpoints include CD28 - a family of receptors expressed on T cells - and their ligand known as B7 proteins that are expressed on the surface of tumour cells and antigen-presenting cells. The inhibitory immune checkpoints include cytotoxic T-lymphocyte-associated protein 4 (CTLA-4), and programmed cell death protein-1 (PD-1); programmed death-ligand (PD-L)1 and PD-L2 are the ligands to the PD-1 checkpoint. Immune checkpoint inhibitors (ICIS) are monoclonal antibodies that block the inhibitory immune checkpoints, including CTLA-4, PD-1 and PD-L1, resulting in activation of T-lymphocytes to exert their antitumour immune responses. ${ }^{2}$

The ICIs that are approved by the US Food and Drug Administration (FDA) include anti-CTLA-4 (ipilimumab), anti-PD-1 (nivolumab, pembrolizumab, cemiplimab) and anti-PDL-1 (avelumab, atezolizumab and durvalumab) agents. The FDA-approved indications for ICIs include malignant melanoma, small cell lung cancer, non-small cell lung cancer, renal cell carcinoma, hepatocellular carcinoma, squamous cell carcinoma of head and neck, metastatic colorectal cancer, metastatic urothelial cancer, cervical cancer, triple-negative breast cancer, refractory Hodgkin's lymphoma, gastric cancer, gastro-oesophageal junction cancer, primary mediastinal large B-cell lymphoma and metastatic Merkel cell carcinoma. ${ }^{3}$

As inhibitory immune checkpoints are important for immune tolerance to prevent development of autoimmune disorders, ICIs are associated with various autoimmune adverse events, known as immune-related adverse events (irAEs). Although any organ in the body can be affected, endocrine organs are commonly involved in irAEs, which are known as endocrinopathies. With increasing use of ICIs in the management of patients with advanced cancer, the incidence of endocrine adverse events is also increasing. Each $\mathrm{ICl}$ subgroup has varying propensity to cause a particular type of endocrinopathy and the onset time also varies. The aim of this article is to critically review the irAEs related to the use of ICIS, with special reference to the endocrinopathies, in order to enhance the knowledge of the endocrinologists, physicians and oncologists to facilitate early diagnosis and accurate treatment of these adverse effects. The currently available ICls with their year of FDA approval, frequency of administration and immunoglobulin isotypes are shown in Table 1. 
Table 1: An overview of currently available immune checkpoint inhibitors

\begin{tabular}{|c|c|c|c|c|}
\hline Immune checkpoint inhibitor & Monoclonal antibody & Target specificity & Antibody subtype & FDA approval (year) \\
\hline \multirow{2}{*}{$\begin{array}{l}\text { Anti-CTLA-4 } \\
\text { Monoclonal antibody }\end{array}$} & Ipilimumab & Every 3 weeks & IgG1 & 2011 \\
\hline & Tremelimumab & Every 4 weeks & IgG2 & Not yet \\
\hline \multirow{3}{*}{$\begin{array}{l}\text { Anti-PD-1 } \\
\text { Monoclonal antibody }\end{array}$} & Nivolumab & Every 2 or 4 weeks & IgG4 & 2014 \\
\hline & Pembrolizumab & Every 3 or 6 weeks & IgG4 & 2014 \\
\hline & Cemiplimab & Every 3 weeks & IgG4 & 2018 \\
\hline \multirow{3}{*}{$\begin{array}{l}\text { Anti-PD-L1 } \\
\text { Monoclonal antibody }\end{array}$} & Avelumab & Every 2 weeks & $\operatorname{lgG1}$ & 2017 \\
\hline & Atezolizumab & Every 2 weeks & $\operatorname{lgG1}$ & 2016 \\
\hline & Durvalumab & Every 2 weeks & $\operatorname{lgG1}$ & 2017 \\
\hline
\end{tabular}

Frequency is the minimal interval between two doses. ${ }^{3}$

CTLA-4 = cytotoxic T-lymphocyte-associated protein 4; FDA = US Food and Drug Administration; IgG = immunog/obulin G; PD-1 = programmed cell death protein 1; $P D-L 1=$ programmed death-ligand 1 .

\section{Organ-specific non-endocrine immune-related adverse events of immune checkpoint inhibitors}

The irAEs of ICls may affect almost every organ system of the body, including the gastrointestinal system, respiratory system, cardiovascular system, musculoskeletal system, nervous system, liver, kidneys, skin and blood.

\section{Cutaneous immune-related adverse events}

Cutaneous toxicity is the most common irAE, ranging from pruritus, maculopapular rash or vitiligo, to severe reactions like Stevens-Johnson syndrome and toxic epidermal necrolysis. ${ }^{4}$ Cutaneous toxicity has been reported in $45-65 \%$ of patients treated with ipilimumab, 30-40\% of patients treated with anti-PD-1 inhibitors, and in $62 \%$ of cases on combination therapy with ipilimumab and anti-PD-1 inhibitors. ${ }^{5-8}$ However, severe symptoms are rare and usually do not require discontinuation of immunotherapy. Mild skin reactions, other than vitiligo, often appear within 3-6 weeks and are reversible. Vitiligo-like depigmentation has been reported in more than $25 \%$ of patients with stage III or IV advanced melanoma receiving nivolumab or pembrolizumab and is usually associated with a better response to anti-PD-1 therapy. ${ }^{9}$ Rare skin complications that may occur during combined anti-PD-1 and anti-CTLA-4 monoclonal antibody therapy include erythrodysaesthesia syndrome, urticaria, toxic epidermal necrolysis and hypersensitivity

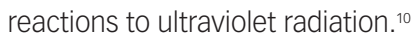

ICls can be continued in patients experiencing grade 1 or 2 skin reactions with the use of emollients, sun protection, mild topical corticosteroids and/or antihistamines. ${ }^{4,711}$ In patients with grade 3 skin reactions, therapy with ICls should be withheld, and steroid administration (prednisolone 0.5-1.0 mg/kg or intravenous methylprednisolone $0.5-1.0 \mathrm{mg} / \mathrm{kg}$ ) may be needed. Restarting immunotherapy is only possible if the severity of skin lesions become grade 1 or 2 . Grade 4 skin reactions mandate urgent dermatological consultation, skin biopsy and administration of methylprednisolone 1-2 mg/kg 1-2 times daily. ICls should be permanently discontinued in such cases. ${ }^{4,7,11}$

\section{Gastrointestinal toxicity}

Gastrointestinal irAEs are the next common manifestations of $\mathrm{ICl}$ use and occur more often in patients receiving combination anti-CTLA-4/anti-PD-1 (44\%), and single agent CTLA-4 therapy (33\%) than those on single-agent anti-PD-1 therapy (20\%). ${ }^{12}$ A mortality rate of $1.1 \%$ from ipilimumab-related colitis is reported. ${ }^{13}$ Severity of toxicity appears dose-dependent; for example, up to $10 \%$ with ipilimumab $10 \mathrm{mg} / \mathrm{kg}$ versus 6\% with $3 \mathrm{mg} / \mathrm{kg} .{ }^{14}$ Symptoms usually start 6-7 weeks after treatment initiation, with onset often later for anti-PD-1 than
anti-CTLA-4, and diarrhoea is quite common. Although the descending colon is the most affected area of bowel, enteritis, oesophagitis and gastritis are also reported with occasional complications, such as toxic megacolon, ulceration, perforation and intra-abdominal abscess and perforation. ${ }^{12,15-17}$

The European Society of Medical Oncology and the American Society of Clinical Oncology guidelines recommend that mild cases be treated symptomatically with a low-fibre diet, oral rehydration and loperamide. ${ }^{7.18}$ Treatment should be initiated with oral prednisolone or budesonide for moderate cases, and intravenous methylprednisolone for more severe/non-resolving cases. Further usage of ICls should be withheld until symptoms resolve. Infliximab is recommended in the absence of steroid response. ${ }^{19}$ There is no clinical evidence for the use of prophylactic corticosteroids to prevent gastrointestinal toxicity. Vedolizumab ( $\alpha 4 \beta 7$ integrin inhibitor) and faecal microbiota transplant may be tried in steroid-refractory cases. ${ }^{20,21}$ Drug-induced pancreatitis is a rare complication of anti-PD-1/PD-L1 agents ( $<1 \%)$, although asymptomatic pancreatic enzyme elevation is much more common. ${ }^{22}$

\section{Pulmonary immune-related adverse events}

Pulmonary toxicity includes pneumonitis, and rarely, sarcoid-like reactionsand pleuraleffusions. Inameta-analysisinvolving2,716 patients, the incidence of any-grade pneumonitis was $4.6 \%$ with combination therapy and $2.1 \%$ with monotherapy. ${ }^{23}$ Mortality rates from pneumonitis are between $1 \%$ and $2 \% .{ }^{24}$ The incidence of pneumonitis with PD-1 axis inhibition is higher than with that of CTLA-4. Non-small cell lung cancers and renal cell carcinomas are associated with higher risk of pneumonitis compared with melanoma, as is prior exposure to radiotherapy. ${ }^{25}$ High-resolution computed tomography (CT) is the diagnostic test for pneumonitis, and radiological patterns of acute interstitial pneumonia, cryptogenic organizing pneumonia, hypersensitivity pneumonitis or non-specific interstitial pneumonia may be seen typically involving lower lung lobes.22,25 Other investigations, such as bronco-alveolar lavage and transbronchial biopsy may be useful for diagnosis in some cases. ${ }^{22}$

Treatment depends on the severity of involvement, with subclinical radiographic changes classified as grade 1 pneumonitis (one-third of cases) requiring only treatment cessation until spontaneous resolution. Grade 2 pneumonitis, characterized by mild dyspnoea and cough, is managed with oral steroids tapered over a month on symptom resolution. Grades 3 or 4 (20-40\% of cases), defined by severe and life-threatening symptoms, require hospitalization and high-dose intravenous methylprednisolone $1-4 \mathrm{mg} / \mathrm{kg} /$ day. Other agents, including 
infliximab, mycophenolate, cyclophosphamide and tocilizumab, may be tried in non-responders. ${ }^{25}$ Recurrence rates of $25-33 \%$ are observed on rechallenge in grade 1 or 2 disease. ${ }^{22,25}$

\section{Hepatic adverse effects}

Hepatotoxicity is frequently asymptomatic and is identified by transaminitis, which occurs nearly 6-14 weeks after receiving therapy. ${ }^{12}$ Severe hepatotoxicity is rare. Hepatitis is more frequent with dual therapy (25-30\% of any grade and $15 \%$ of grade 3 or 4 ) than with single-agent $\mathrm{ICl}$ therapy ( $5-10 \%$ of any grade and $1-2 \%$ of grade 3 or 4$).{ }^{25}$ Lobular hepatitis, characterized by hepatocellular dysfunction is common, while ductular injury with jaundice and cholestasis is uncommon, and demonstrates poor corticosteroid response..$^{25-29} \mathrm{Ultrasonography} \mathrm{and} \mathrm{CT} \mathrm{scan} \mathrm{may} \mathrm{show}$ steatosis, hepatomegaly, gallbladder oedema and lymphadenopathy, while liver biopsy may reveal diagnostic histological patterns. ${ }^{12} \mathrm{ICI}$-related hepatotoxicity requires discontinuation of the culprit drug and high-dose corticosteroids. Additionally, a second-line immunomodulatory agent, such as mycophenolate mofetil and/or tacrolimus, may be needed, and in severe cases, anti-thymocyte globulin may be used. ${ }^{25,30}$

\section{Renal immune-related adverse events}

varying degrees of acute kidney injury with an overall incidence of $17 \%$ have been reported among patients treated with ICIs, of which, 2.2-5.0\% may be related to direct insult from the drugs. ${ }^{31}$ Tubular, interstitial and glomerular disorders of different patterns are found in patients with renal involvement. Lower baseline renal function and co-administration of other nephrotoxic medications increase the risk. Although various renal imaging modalities may aid the work-up, histology is the gold-standard tool that may be necessary in some cases for diagnosis. ${ }^{31,32}$ Discontinuation of $\mathrm{ICls}$ and use of steroids are indicated in moderate to severe cases.

\section{Cardiovascular toxicity}

Although myocarditis is the most common cardiotoxic feature of $\mathrm{ICl}$ therapy, varying degrees of pericarditis, arrhythmias, cardiomyopathy and vasculitis are also occasionally seen. ${ }^{33-35}$ Overall prevalence of myocarditis is $1.14 \%$, which may increase to $2.4 \%$ when anti-PD-1 and anti-CTLA-4 agents are used in combination. ${ }^{33,34}$ Median time for occurrence of cardiotoxicity is 2 months, with most cases presenting within 3 months of initiation. Investigations, such as electrocardiography, cardiac enzymes and echocardiography are non-specific, and the gold-standard test for myocarditis is cardiac magnetic resonance imaging (MRI). ${ }^{33}$ Endomyocardial biopsy rarely becomes necessary. Treatment of cardiotoxicity is with discontinuation of ICIs, supportive care, corticosteroids, and less commonly, other immunosuppressants. ${ }^{33,35}$

\section{Musculoskeletal immune-related adverse events}

various rheumatological manifestations are encountered in up to $7 \%$ of patients treated with $\mathrm{ICls}$, ranging from arthralgias, myalgias, inflammatory arthritis and polymyalgia rheumatica, to polymyositis and sicca manifestations. ${ }^{36,37}$ These features usually indicate better therapeutic response to ICIs. For grade $\geq 2$ adverse events, including inflammatory arthritis, a referral to a rheumatologist and therapy with a tapering course of corticosteroids are necessary. ${ }^{38}$ In corticosteroid non-responders, other immunomodulatory agents may be indicated.

\section{Neurological manifestations}

Neurotoxicity is rather uncommon when compared to other toxic effects of $\mathrm{ICl}$ therapy. Manifestations include peripheral neuropathy, meningitis, encephalopathy, myositis and myasthenia gravis.39-41 Treatment involves discontinuation of ICIS, glucocorticoids and, occasionally, other immunosuppressants.
Table 2: Summary of organ-specific immune-related adverse events of immune checkpoint inhibitor treatment

\begin{tabular}{|c|c|}
\hline Organ involved & Various non-endocrine irAEs \\
\hline Cutaneous & $\begin{array}{l}\text { Vitiligo, psoriasis, urticaria, erythrodysaesthesia } \\
\text { syndrome, DRESS syndrome, Steven-Johnson } \\
\text { syndrome, toxic epidermal necrolysis and } \\
\text { hypersensitivity reaction to ultraviolet radiation }\end{array}$ \\
\hline Gastrointestinal & Colitis, enteritis, gastritis, pancreatitis \\
\hline Pulmonary & Pneumonitis, pleuritis and sarcoid-like granulomatosis \\
\hline Hepatic & Hepatitis and cholestasis \\
\hline Renal & Different types of nephritis and acute kidney injury \\
\hline Cardiovascular & Myocarditis, pericarditis and vasculitis \\
\hline Musculoskeletal & $\begin{array}{l}\text { Arthralgia, myalgia, inflammatory arthritis, polymyalgia } \\
\text { rheumatica, polymyositis, sicca manifestations and } \\
\text { sarcoidosis }\end{array}$ \\
\hline Neurological & $\begin{array}{l}\text { Encephalitis, meningitis, peripheral neuropathy, } \\
\text { myositis and myasthenia gravis }\end{array}$ \\
\hline Ophthalmic & $\begin{array}{l}\text { Scleritis, episcleritis, uveitis, retinitis, conjunctivitis, } \\
\text { blepharitis, inflammatory orbitopathy, keratitis, optic } \\
\text { neuropathy, serous retinal detachment, extraocular } \\
\text { myopathy, atypical chorioretinal lesions, immune } \\
\text { retinopathy and neuroretinitis }\end{array}$ \\
\hline Haematological & $\begin{array}{l}\text { Haemolytic/aplastic anaemia, thrombocytopenia, } \\
\text { neutropenia, agranulocytosis }\end{array}$ \\
\hline
\end{tabular}

DRESS = drug reaction with eosinophilia and systemic symptoms; irAES = immune-related adverse events

\section{Ophthalmic immune-related adverse events}

ophthalmic events occur in $<1 \%$ of patients, and range from scleritis, episcleritis, uveitis, retinitis, conjunctivitis, blepharitis, inflammatory orbitopathy and keratitis, to optic neuropathy, serous retinal detachment, extraocular myopathy, atypical chorioretinal lesions, immune retinopathy and neuroretinitis. ${ }^{42,43}$ Treatment involves topical steroids in mild cases, to discontinuation of ICls with systemic steroids and immunosuppressants in severe disease.

\section{Haemotoxicity}

commonly reported haematological manifestations of $\mathrm{ICl}$ toxicity are thrombocytopaenia, haemolytic anaemia and aplastic anaemia. ${ }^{44}$ Agranulocytosis and neutropenia are less often described. Management is usually successful with corticosteroids; other therapeutic strategies, such as intravenous immunoglobulins, rituximab and transfusion of blood components are rarely needed. Table 2 summarizes the organ-specific irAEs of ICl treatment.

\section{Endocrinopathies: endocrine immune-related adverse events of immune checkpoint inhibitors}

The most frequent endocrine irAE following the use of any $\mathrm{ICl}$ monotherapy is hypothyroidism, with hypophysitis being the next most common. ${ }^{45}$ Other endocrine irAEs, including hyperthyroidism, thyroiditis, primary adrenal insufficiency, autoimmune diabetes and hypoparathyroidism, are infrequent. ${ }^{45}$ Among patients on anti-CTLA-4 agent monotherapy, the most frequent endocrine irAE is hypophysitis, whereas among patients on anti-PD-1/PD-L1 agent monotherapy, the most frequent irAE is hypothyroidism. Patients on combination therapy with anti-CTLA-4 agents and anti-PD-1/PD-L1 agents demonstrate a higher incidence of hypothyroidism (10.2-16.4\%), hyperthyroidism (9.4-10.4\%), hypophysitis (8.8-10.5\%) and primary adrenal insufficiency (PAl; 5.2-7.6\%). However, combination therapy rarely induced more 
thyroiditis (3.8-4.6\%) and autoimmune diabetes (2.0\%) cases compared to monotherapy. ${ }^{45}$ Fatigue is a common symptom, occurring in patients with cancer on traditional cancer therapies. However, in a patient on immunotherapy, fatigue may be a symptom of endocrinopathies like adrenal insufficiency, thyroid dysfunction and diabetes, and these symptoms mandate an endocrine work-up.

\section{Hypophysitis}

With regards to monotherapy, the incidence of hypophysitis (inflammation of the pituitary gland) is highest with the anti-CTLA-4 agent ipilimumab, with an incidence of $5.6 \%$ (95\% confidence interval [CI] 3.9-8.1). This is followed by tremelimumab, which is associated with an incidence of $1.8 \%$ (95\% Cl 1.1-2.9). ${ }^{45}$ The disparity in incidence of hypophysitis between ipilimumab and tremelimumab is probably due to the difference in their immunoglobin subclasses (immunoglobulin G [IgG]1 versus IgG2, respectively). Anti-PD-1 agents, like nivolumab $(0.5 \%$; $95 \% \mathrm{Cl} 0.2-1.2)$ or pembrolizumab (1.1\%; 95\% Cl 0.5-2.6), are rare causes of hypophysitis and the incidence is extremely rare with anti-PD-L1 agents. ${ }^{45}$ When used in combination therapy, the incidence of hypophysitis is $8.8-10.5 \%$, with the incidence being $8.8 \%$ (95\% Cl 6.2-12.4) for ipilimumab-nivolumab, and $10.5 \%$ (95\% Cl 6.5-16.4) for ipilimumab-pembrolizumab combination. ${ }^{45}$

The incidence of hypophysitis is twofold greater for high-dose ipilimumab (10 $\mathrm{mg} / \mathrm{kg}$ ) in comparison to low-dose ipilimumab $(3 \mathrm{mg} / \mathrm{kg}$ every 3 weeks for four doses). ${ }^{14}$ Moreover, the incidence was high among older age groups and males. ${ }^{46}$ Anti-CTLA-4 agent-induced hypophysitis usually develops on an average of 10.5 weeks (95\% Cl 9.8-11.2, $\mathrm{p}<0.001)$ after the onset of therapy, whereas the timing of onset of anti-PD-1/PD-L1-induced hypophysitis is extremely variable, with some cases developing in few weeks - mostly at an average of 27 weeks, and a few developing after 1 year. ${ }^{47}$ The mean time of onset for anti-PD-1 is 27 weeks (95\% Cl 20.9-33.1, p<0.001), and for anti-PD-L1 is 27.8 weeks (95\% Cl 0-58, $\mathrm{p}=0.001)$. $^{47}$

The diagnosis of $\mathrm{ICl}$-induced hypophysitis requires a high index of suspicion and is based on clinical symptoms and imaging. ${ }^{47} \mathrm{ICl}$-induced hypophysitis is clinically distinct from primary hypophysitis in its male preponderance, abrupt onset, older age, severe central adrenal deficiency, lower incidence of posterior pituitary and optic chiasmal involvement, and often persistent hypopituitarism. Among ICl-induced hypophysitis, anti-CTLA-4 therapy-induced hypophysitis is clinically distinct from anti-PD-1/PD-L1 therapy-induced hypophysitis in that the former is associated with symptoms of mass effect (headache or visual-field defects), panhypopituitarism, and significant changes on MRI with diffusely enlarged pituitary, widened pituitary stalk or altered contrast enhancement. In contrast, anti-PD-1/PD-L1 therapy-induced hypophysitis is associated with isolated severe adrenocorticotropic hormone (ACTH) deficiency without any symptoms of mass effect or MRI changes. ${ }^{47}$

The presenting symptom of anti-PD-1/PD-L1-induced hypophysitis is that of hypoadrenalism, whereas anti-CTLA-4-induced hypophysitis presents with hypothyroidism, hypogonadism, headache and visual disturbances. ${ }^{47}$ However, at the time of diagnosis of hypophysitis, nearly equal numbers of patients in either group (97\% in anti-PD-1/PD-L1 agent versus $95 \%$ in anti-CTLA-4 agent) exhibit central adrenal insufficiency. Among the anti-CTLA-4 group, 85\% manifest with central hypothyroidism and 75\% with central hypogonadism. Moreover, deficiencies of growth hormone and prolactin occur in $27 \%$ of patients on an anti-PD-1/PD-L1 agent and $25 \%$ of patients on an anti-CTLA-4 agent. Diabetes insipidus is rare (2\%). MRI is abnormal in $81 \%$ of cases of hypophysitis following anti-CTLA-4 agents, whereas it shows changes in only $18 \%$ of cases following anti-PD-1/PD-L1. These distinctive clinical features are important, as those patients without severe mass effect, or those not expected to have severe mass effect, should not be unnecessarily treated with high-dose steroids. ${ }^{47}$

Anti-CTLA-4 agent-induced hypophysitis can be explained by the expression of the CTLA-4 in the anterior pituitary cells that secrete $\mathrm{ACTH}$, thyroid-stimulating hormone (TSH) and follicle-stimulating hormone (FSH). ${ }^{48}$ CTLA-4 expression results in the development of antibodies directed against TSH-, FSH- or ACTH-secreting cells of the pituitary gland in patients with hypophysitis who were negative for these antibodies at baseline. Moreover, CTLA-4 expression is seen in normal pituitary cells and pituitary adenomas. ${ }^{49}$ There is significant variability among individuals in the expression of CTLA-4 in the anterior pituitary cells, and this could explain why only some patients develop hypophysitis after administration of an anti-CTLA-4 agent. Anti-CTLA-4, being an IgG molecule, binds to and activates the classical complement pathway to induce an antibody-dependent cell-mediated cytotoxicity (type 2 hypersensitivity reaction), and these events further trigger autoimmune damage of the pituitary gland, resulting in hypophysitis (type 4 hypersensitivity reaction). ${ }^{50}$ The pathogenesis of anti-PD-1/PD-L1-induced hypophysitis is unknown, though the expression of PD-1 on ACTH-producing anterior pituitary cells could explain the isolated severe ACTH deficiency. ${ }^{47}$

Lymphocytic hypophysitis is characterized by infiltration of the pituitary gland by both T and B lymphocytes. However, the histopathological characteristics of ICl-related hypophysitis are not well established, as only limited numbers of biopsies are available from such cases. ${ }^{51}$ In one series, high CTLA-4 expression was associated with aggressive necrotizing hypophysitis mediated by T-cell dependent (type IV) and IgG-dependent (type II) immune mechanisms, resulting in necrosis and distortion of the anterior pituitary architecture. ${ }^{50}$

Diagnostic work-up of patients with suspected ICl-induced hypophysitis should include serum electrolytes, 8 am cortisol, ACTH, synacthen test (if indicated), TSH and free thyroxine (FT4), FSH, luteinizing hormone (LH) and oestradiol (premenopausal women) or testosterone (men), prolactin and insulin-like growth factor 1 (IGF-1). ${ }^{18}$ If symptoms of diabetes insipidus are present, evaluation with urine-specific gravity, urine and serum osmolality is indicated. MRI of the brain with dedicated pituitary sections is indicated in the presence of multiple hormone deficiencies with or without headache and visual field changes. Low cortisol with low or inappropriately normal ACTH, low FT4 with low or inappropriately normal TSH, low testosterone or oestradiol with low or inappropriately normal $\mathrm{LH} / \mathrm{FSH}$ with or without hypernatraemia is diagnostic of hypophysitis. ${ }^{18}$

All patients on ICIs should be monitored for hypophysitis symptoms and, once hypophysitis is diagnosed, replacement therapy should be initiated with low-dose steroids. Central hypoadrenalism is largely irreversible, whereas gonadotrophin and TSH deficiencies are often reversible. ${ }^{52}$ Hence, initiation of levothyroxine and sex hormone replacement can be delayed. There is no significant difference between anti-CTLA- 4 and anti-PD-1/PD-L1 agents as far as replacement therapy is concerned. Hypophysitis resolves rapidly once low-dose steroids are initiated and post-therapy MRI might even appear normal. ${ }^{46}$ Therefore, a normal MRI does not rule out hypophysitis. High-dose steroids should only be used in cases with severe headache and visual disturbances, as they can decrease the efficacy of $\mathrm{ICls}$, worsen the outcome and increase mortality. ICls can be suspended/delayed until the acute symptoms of 
hypophysitis are resolved; however, most patients will be able to resume and continue them as previously planned. ${ }^{47}$

The standard steroid replacement is with hydrocortisone $20 \mathrm{mg}$ split into three administrations: $10 \mathrm{mg}$ in the morning, $5 \mathrm{mg}$ at lunch time and $5 \mathrm{mg}$ in the early evening. The last dose should be administered before $6 \mathrm{pm}$ to avoid polyuria and insomnia. In emergency situations, intravenous hydrocortisone should be given at a dose of $100 \mathrm{mg}$ followed by 50 mg every 6 hours or using continuous hydrocortisone infusion at a rate of $1-2 \mathrm{mg} /$ hour. An alternative regimen to oral hydrocortisone is twice daily cortisone acetate at a dose of $25 \mathrm{mg}$ in the morning and $12.5 \mathrm{mg}$ in the mid-afternoon. ${ }^{47}$ Thyroid hormone replacement should be commenced several days after corticosteroid replacement is initiated, to prevent adrenal crisis. The usual dose for levothyroxine is $1.6 \mu \mathrm{g} / \mathrm{kg} /$ day. ${ }^{18}$ Adjustment of levothyroxine dose should be based on FT4 (not TSH), with an aim to keep FT4 at the middle or upper half of the reference range.

Nearly one-third of patients on $\mathrm{ICl}$ therapy would eventually require high-dose steroids for the treatment of non-endocrine irAEs, and long-term exogeneous steroid administration can result in hypothalamic-pituitary-adrenal (HPA) axis suppression. Hence, early-morning cortisol should not be measured to diagnose central hypoadrenalism in these patients while on high-dose corticosteroid therapy. However, early-morning cortisol can be measured once the corticosteroid dose is weaned down to approximately $5 \mathrm{mg}$ prednisolone equivalent. If the cortisol level is $<100 \mathrm{nmol} / \mathrm{L}$, it strongly suggests adrenal suppression. Corticosteroid replacement should be continued and the possibility of silent hypophysitis resulting in ACTH deficiency should be considered. If the early-morning cortisol level is between 100 and $500 \mathrm{nmol} / \mathrm{L}$, there is a possibility of adrenal suppression and hence a short synacthen test should be done. If the early-morning cortisol is $>500 \mathrm{nmol} / \mathrm{L}$, it indicates normal HPA axis and hence, the corticosteroid can be stopped. ${ }^{53-55}$

A standardized grading system proposed by the National Cancer Institute in the USA for adverse event reporting in cancer clinical trials is known as the Common Terminology Criteria for Adverse Events (CTCAE). According to the current CTCAE (version 5), ICl-induced hypophysitis can be graded into grade 1: asymptomatic or with mild symptoms; grade 2 : with moderate symptoms or limitation of age-appropriate instrumental activities of daily living; grade 3 : with severe, but not life-threatening symptoms or limitation of self-care activities of daily living; grade 4 : with life-threatening consequences; and grade 5: resulting in death. ${ }^{56}$ The management appropriate for various grades of adverse events is given in Table 3.

\section{Thyroid dysfunction}

ICls, especially anti-PD-1/PD-L1 monoclonal antibodies, are associated with a spectrum of primary thyroid disorders, including painless thyroiditis, overt hyperthyroidism, subclinical hyperthyroidism, subclinical hypothyroidism and overt hypothyroidism.45 Painless thyroiditis is characterized by a hyperthyroid phase followed by euthyroidism or hypothyroidism, with negative TSH receptor antibodies (TRAb), decreased uptake on radioactive iodine scan (RAIU) or decreased uptake on technetium pertechnetate ${ }^{\left.{ }^{99 m} \mathrm{TC}\right)}$ scan and/or raised uptake on 18-fluorodeoxyglucose positron emission tomography $\left({ }^{18}\right.$ FDG-PET) scan.

Hypothyroidism is the most frequent thyroid disorder related to $\mathrm{ICl}$ use, followed by hyperthyroidism and painless thyroiditis. ICIs may rarely cause precipitation of a thyroid storm. ${ }^{57}$ The pathogenesis of thyroid dysfunction (hyperthyroidism followed by either euthyroidism or hypothyroidism) in patients using an $\mathrm{ICl}$ is due to a painless destructive thyroiditis, mediated by cytotoxic $T$ cells against the thyroid gland. ${ }^{58}$ Destructive thyroiditis develops within first few weeks of ICI therapy and a transition occurs from initial phase of hyperthyroidism to a subsequent phase of hypothyroidism within 3-6 weeks. Rarely, hypothyroidism may develop simultaneously with the onset of painless thyroiditis. The phase of hyperthyroidism is typically mild, asymptomatic and transient. Hyperthyroidism is associated with elevated thyroglobulin levels, which become normalized with the subsequent development of hypothyroidism. ${ }^{59}$

Though ICl-induced hyperthyroidism could mostly be due to destructive thyroiditis, it may rarely be due to the development of ICI-related Graves' disease, especially with anti-CTLA-4 monoclonal antibodies. ${ }^{60,61}$ TRAb status, RAIU and colour flow Doppler ultrasonography can distinguish between destructive thyroiditis (negative TRAb, low RAIU and low blood flow on doppler) and Graves' disease (positive TRAb, high RAIU and high blood flow on doppler). However, recent iodinated contrast media administration could suppress the RAIU in a patient with Graves' disease. Hence, an RAIU study should be done only in patients with persistent hyperthyroidism who have not had any iodinated contrast media exposure for at least a month. ${ }^{62}$ lodine-induced hyperthyroidism is another possible aetiology for hyperthyroidism in these patients on ICIS, who also require repeated iodinated contrast media administration for radiological investigations. ${ }^{63}$

The increased incidence of thyroid dysfunction in patients on anti-PD-1 antibodies compared with anti-PD-L1 antibodies or anti-CTLA-4 antibodies is due to the fact that the normal thyroid gland tissue expresses both PD-L1 and PD-L2 molecules, and PD-L2 blockade results in thyroid dysfunction. ${ }^{64}$ Patients with pre-existing subclinical autoimmune thyroid disease in the form of positive thyroid autoantibodies (thyroid peroxidase antibodies) are at increased risk of developing ICl-induced destructive thyroiditis and thyroid dysfunction. ${ }^{65}$

Hashimoto's and painless destructive thyroiditis are classically associated with infiltration of the thyroid gland by both $\mathrm{T}$ and B lymphocytes. ${ }^{66}$ However, the histopathological features of ICl-related thyroid dysfunction are less clear as the number of biopsies available from such cases, to date, are limited. One series showed a high PD-L1 expression associated with chronic Iymphocytic infiltration, granuloma formation and destruction of thyroid follicles. ${ }^{66}$ Necrotic cells, lymphocytes and histiocytes were demonstrated from biopsies in another series. ${ }^{67}$

Higher doses of $\mathrm{ICl}$ therapy are associated with increased incidence of hypothyroidism (2.2\% versus $1.9 \%)$ and destructive thyroiditis $(1.4 \%$ versus $0.6 \%$ ) in patients on ipilimumab $10 \mathrm{mg} / \mathrm{kg}$ compared with $3 \mathrm{mg} / \mathrm{kg} .{ }^{64}$ When used as monotherapy, the incidence of hypothyroidism is highest with pembrolizumab 8.5\% (95\% Cl 7.5-9.7), followed by nivolumab 8.0\% (95\% Cl 6.4-9.8), atezolizumab 6.0\% (95\% Cl 4.2-8.4), avelumab $5.5 \%$ (95\% Cl 3.5-8.7), durvalumab 4.7\% (95\% Cl 2.5-8.8) and ipilimumab $3.8 \%(95 \% \mathrm{Cl} 2.6-5.5) .45$ The incidence of thyroid dysfunction, including hypothyroidism, hyperthyroidism and painless thyroiditis, associated with tremelimumab, was up to $5.2 \%$ in a phase III randomized clinical trial compared with chemotherapy. ${ }^{68}$ As a combination therapy, the incidence of hypothyroidism is significantly higher compared with monotherapy, and is in the range of $10.2-16.4 \%$. The incidence of hypothyroidism associated with ipilimumab-nivolumab combination is $16.4 \%$ (95\% Cl 11.7-22.5), ipilimumab-pembrolizumab combination is $15.1 \%(95 \% \mathrm{Cl} 10.6-21.8)$ and durvalumab-tremelimumab combination is $10.2 \%$ (95\% Cl 5.6-17.9). ${ }_{4}^{45}$ 
Table 3: Management of immune checkpoint inhibitor-mediated endocrinopathies ${ }^{18,56,76}$

\begin{tabular}{|c|c|c|c|c|c|c|c|}
\hline & \multicolumn{2}{|l|}{ Grade 1} & \multicolumn{2}{|l|}{ Grade 2} & Grade 3 & Grade 4 & Grade 5 \\
\hline \multirow[t]{2}{*}{ Hypophysitis } & \multicolumn{2}{|c|}{ Asymptomatic or mild symptoms } & \multicolumn{2}{|c|}{$\begin{array}{l}\text { Moderate symptoms, limiting instrumental } \\
\text { ADL }\end{array}$} & $\begin{array}{l}\text { Severe symptoms, limiting } \\
\text { self-care ADL }\end{array}$ & $\begin{array}{l}\text { Life-threatening } \\
\text { consequences }\end{array}$ & Death \\
\hline & \multicolumn{4}{|c|}{$\begin{array}{l}\text { Consider holding } \mathrm{ICI} \text { until stabilized on replacement therapy. Adequate hormone } \\
\text { replacement }\end{array}$} & \multicolumn{2}{|c|}{$\begin{array}{l}\mathrm{Hold} \mathrm{ICl} \text {, restart after recovery from adrenal } \\
\text { crisis and stabiliation of symptoms. Treat as } \\
\text { adrenal crisis }\end{array}$} & \\
\hline \multirow[t]{2}{*}{ Hyperthyroidism } & \multicolumn{2}{|l|}{ Asymptomatic } & \multicolumn{2}{|c|}{ Symptomatic, limiting instrumental ADL } & $\begin{array}{l}\text { Severe symptoms, limiting } \\
\text { self-care ADL }\end{array}$ & $\begin{array}{l}\text { Life-threatening } \\
\text { consequences }\end{array}$ & Death \\
\hline & \multicolumn{2}{|c|}{ Continue ICl; monitor every 2-3 weeks } & \multicolumn{2}{|c|}{$\begin{array}{l}\text { Consider holding } \mathrm{ICl} \text {; start non-selective } \\
\text { beta-blocker; consider thionamide if } \\
\text { hyperthyroidism persisting }>6 \text { weeks }\end{array}$} & \multicolumn{2}{|c|}{$\begin{array}{l}\text { Hold ICI until symptom relief; steroids +/- SSKI } \\
\text { for severe symptoms/impending storm; } \\
\text { non-selective beta-blockers for symptom } \\
\text { relief; thionamide in Graves' disease }\end{array}$} & \\
\hline \multirow[t]{2}{*}{ Hypothyroidism } & $\begin{array}{l}\text { Asymptomatic TSH } \\
<10 \mathrm{mIU} / \mathrm{L}\end{array}$ & $\begin{array}{l}\text { Asymptomatic TSH } \\
>10 \mathrm{mIU} / \mathrm{L}\end{array}$ & \multicolumn{2}{|c|}{ Symptomatic, limiting instrumental ADL } & $\begin{array}{l}\text { Severe symptoms, limiting } \\
\text { self-care } A D L\end{array}$ & $\begin{array}{l}\text { Life-threatening } \\
\text { consequences }\end{array}$ & Death \\
\hline & $\begin{array}{l}\text { Continue ICl use; } \\
\text { monitor TSH/FT4 } \\
\text { closely }\end{array}$ & $\begin{array}{l}\text { Use thyroxine; } \\
\text { monitor every } \\
4 \text { weeks }\end{array}$ & \multicolumn{2}{|c|}{$\begin{array}{l}\text { Consider holding } \mathrm{ICl} \text { until asymptomatic. } \\
\text { Use thyroxine; monitor every } 4 \text { weeks. Test } \\
\text { every } 6 \text { weeks while on active } \mathrm{ICl} \text {. }\end{array}$} & \multicolumn{2}{|c|}{$\begin{array}{l}\text { Hold ICI until resolution of symptoms to } \\
\text { baseline with appropriate replacement. May } \\
\text { need IV thyroid hormone replacement in } \\
\text { cases of myxedema }\end{array}$} & \\
\hline \multirow[t]{2}{*}{$\begin{array}{l}\text { Primary adrenal } \\
\text { insufficiency }\end{array}$} & \multicolumn{2}{|l|}{ Asymptomatic } & \multicolumn{2}{|l|}{ Moderate symptoms } & Severe symptoms & $\begin{array}{l}\text { Life-threatening } \\
\text { consequences }\end{array}$ & Death \\
\hline & \multicolumn{2}{|c|}{$\begin{array}{l}\text { Consider holding } \mathrm{ICl} \text { until stable. Use } \\
\text { standard doses of hydrocortisone }+/- \\
\text { fludrocortisone }\end{array}$} & \multicolumn{2}{|c|}{$\begin{array}{l}\text { Consider holding } \mathrm{ICl} \text { until stable. Double } \\
\text { hydrocortisone }+/ \text { - fludrocortisone. Taper } \\
\text { down in 5-10 days to maintenance }\end{array}$} & \multicolumn{2}{|c|}{$\begin{array}{l}\text { Hold ICl. Hydrocortisone } 100 \text { mg followed } \\
\text { by } 50 \text { mg IV every } 6 \text { hourly. Taper down the } \\
\text { hydrocortisone dose in 7-14 days }\end{array}$} & \\
\hline \multirow[t]{3}{*}{$\begin{array}{l}\text { Insulin-dependent } \\
\text { diabetes mellitus }\end{array}$} & \multirow{2}{*}{\multicolumn{2}{|c|}{$\begin{array}{l}\text { Asymptomatic or mild symptoms. FPG } \\
\text { ULN to } 8.9 \mathrm{mmol} / \mathrm{L} ; \text { no DKA or evidence } \\
\text { of T1DM }\end{array}$}} & \multirow{2}{*}{$\begin{array}{l}\text { Moderate } \\
\text { symptoms; able to } \\
\text { perform ADL; FPG } \\
8.9-13.9 \mathrm{mmol} / \mathrm{L}\end{array}$} & \multirow{2}{*}{$\begin{array}{l}\text { DKA or evidence of } \\
\text { T1DM with any FPG } \\
\text { levels } \\
\text { FPG } 13.9-27.8 \mathrm{mmol} / \mathrm{L}\end{array}$} & \multicolumn{2}{|c|}{$\begin{array}{l}\text { Severe or life-threatening symptoms; unable } \\
\text { to perform self-care ADL }\end{array}$} & Death \\
\hline & & & & & FPG $>27.9 \mathrm{mmol} / \mathrm{L}$ & & \\
\hline & \multicolumn{2}{|c|}{$\begin{array}{l}\text { Continue } \mathrm{ICl} \text {. Treat as T2DM. Consider } \\
\text { oral diabetic drugs (OHA) }\end{array}$} & $\begin{array}{l}\text { Consider holding } \\
\mathrm{ICl} \text { until stable. } \\
\text { Titrate OHA or add } \\
\text { insulin }\end{array}$ & $\begin{array}{l}\text { Start insulin: basal } \\
\text { bolus regimen }\end{array}$ & \multicolumn{2}{|c|}{$\begin{array}{l}\text { Hold ICI until stabilized. Start basal bolus } \\
\text { insulin, which is needed for long-term }\end{array}$} & \\
\hline
\end{tabular}

$A D L=$ activities of daily living; $D K A=$ diabetic ketoacidosis; $F P G$ = fasting plasma glucose; FT4 = free thyroxine; ICl = immune check point inhibitor; $I V=$ intravenous;

OHA = oral hypoglycaemic agent; SSKI = saturated solution of potassium iodide; T1/2DM = type 1/2 diabetes mellitus; TSH = thyroid-stimulating hormone; ULN = upper limit of normal.

When used as monotherapy, the incidence of hyperthyroidism is highest with pembrolizumab 3.7\% (95\% Cl 2.8-4.7), followed by nivolumab $2.8 \%$ (95\% Cl 2.1-3.8), avelumab 2.3\% (95\% Cl 0.6-8.6) and ipilimumab 1.4\% (95\% Cl 0.8-2.4)..$^{45}$ Cases of hyperthyroidism have not been reported with atezolizumab and durvalumab. The incidence of hyperthyroidism is significantly higher with combination therapy compared with monotherapy and is in the range of $9.4-10.4 \%$, with the incidence for ipilimumab-nivolumab combination being 9.4\% (95\% Cl 7.1-12.3) and the incidence for ipilimumab-pembrolizumab combination being $10.4 \%$ (95\% Cl 6.6-16.1). Like durvalumab monotherapy, hyperthyroidism is not reported with durvalumab-tremelimumab combination as well. ${ }^{45}$

The incidence of thyroiditis is highest for pembrolizumab $2.3 \%(95 \% \mathrm{Cl}$ 1.2-4.6), followed by ipilimumab $2.1 \%(95 \% \mathrm{Cl} 1.1-4.1)$ and nivolumab $1.6 \%\left(95 \% \mathrm{Cl}\right.$ 0.2-0.2). ${ }^{45}$ Thyroiditis has not been reported with anti-PD-L1 agents including avelumab, atezolizumab and durvalumab. Higher incidence occurs with combination: $4.6 \%(95 \% \mathrm{Cl}$ 2.2-9.3) with ipilimumab-pembrolizumab combination and 3.8\% (95\% Cl 1.4-9.4) with ipilimumab-nivolumab combination. ${ }^{45}$

Clinical features during the phase of hyperthyroidism include tremor, tachycardia, fever, sweating, diarrhoea, fatigue and weight loss. Neck pain is not common in patients with destructive thyroiditis in contrast to patients with subacute thyroiditis. Periodic testing with TSH and FT4 every 4-6 weeks is advised for all patients on ICls. ${ }^{18}$ The same tests should also be conducted in patients with symptoms of hyperthyroidism. High FT4 with suppressed TSH is diagnostic of primary hyperthyroidism. TRAb testing may be considered only if Graves' disease is suspected (thyroid bruit or Graves' ophthalmopathy). Close monitoring with TSH and FT4 every 2-3 weeks should be done to catch the transition to hypothyroidism that occurs with thyroiditis, or to detect persistent hyperthyroidism that is persisting for $>6$ weeks as in Graves' disease. ${ }^{18}$

Management recommendations for $\mathrm{ICl}$-induced hyperthyroidism are given in Table 3. ${ }^{18,56}$ Non-selective beta-blockers, such as propranolol or atenolol, should be used for symptom relief. High-dose glucocorticoids (equivalent to prednisolone $2 \mathrm{mg} / \mathrm{kg} /$ day) should only be used in patients with severe symptoms or in elderly patients with cardiovascular comorbidities. Thionamides, like carbimazole or methimazole, should only be used in patients with suspected Graves' disease..$^{18}$ Adjustment of thionamide dose should be based on FT4 measurements, with an aim to keep FT4 at the upper half of the reference range. The measurement of TSH alone is inadequate, as TSH might remain suppressed for many weeks or months after the initiation of antithyroid therapy, especially in patients with Graves' disease. Treatment with thyroidectomy or radioiodine are options for treatment when Graves' hyperthyroidism is not manageable with antithyroid drugs. ${ }^{69}$ 
Clinical features in the hypothyroidism phase include fatigue, loss of appetite, constipation, bradycardia, dry skin and weight gain. ${ }^{18}$ Periodic testing with TSH and FT4 every 4-6 weeks is advised in patients on ICIs. The same tests are used in patients with symptoms of hypothyroidism. The laboratory picture of primary hypothyroidism includes raised TSH with normal FT4 (subclinical hypothyroidism) or with low FT4 (overt hypothyroidism), while a low FT4 associated with low or inappropriately normal TSH is suggestive of central hypothyroidism associated with hypophysitis. The differentiation between primary and secondary hypothyroidism is particularly important, as thyroid replacement therapy without steroid replacement in the latter will result in precipitation of adrenal crisis. Euthyroid sick syndrome (non-thyroid illness syndrome or low T3 syndrome) is another differential diagnosis characterized by normal or low TSH, normal or low FT4, low FT3 and high reverse T3.

Management recommendations for ICl-induced hypothyroidism, based on CTCAE grades, are given in Table 3. For frail or elderly patients with multiple comorbidities including coronary artery disease, a 'start low, go slow' approach should be implemented, starting at a low dose of 25-50 $\mathrm{\mu g}$ /day of levothyroxine and then slowly titrating up. For people without comorbidities, the ideal body weight should be used for levothyroxine dose calculations, rather than actual body weight. The usual daily dose of levothyroxine is $1.6 \mu \mathrm{g} / \mathrm{kg} /$ day. Adjustment of levothyroxine dose should be based on TSH, with an aim to keep TSH in the lower half of the reference range. If adrenal dysfunction is present (which can develop as simultaneous primary hypothyroidism and PAI or as part of hypophysitis: central hypoadrenalism and central hypothyroidism), levothyroxine should be replaced several days after initiation of steroid replacement. ${ }^{18}$

\section{Primary adrenal insufficiency}

PAl is an infrequent, but severe, life-threatening adverse event following $\mathrm{ICl}$ therapy. It is possible that PAI is underdiagnosed, as it is often difficult to diagnose in patients who are already on steroids for the treatment of other irAES. ${ }^{18} \mathrm{PAl}$ is characterized by insufficient secretion of glucocorticoids with or without insufficient secretion of mineralocorticoids and androgens. PAl is associated with a rise in ACTH and/or renin. Adrenal insufficiency that occurs in patients on ICI therapy could either be central hypoadrenalism caused by hypophysitis, pituitary metastasis, or abrupt withdrawal of exogenous glucocorticoid therapy, or PAI caused by ICl-related adrenalitis, adrenal metastasis or adrenal haemorrhage. The differentiation between central hypoadrenalism and PAl is important, as the area of interest for imaging studies and the agents for treatment are different. Whereas central hypoadrenalism is treated only with hydrocortisone, patients with PAI might require a mineralocorticoid agent, fludrocortisone $100 \mu g /$ day, in addition to either hydrocortisone or prednisolone. ${ }^{70}$

When used alone, the incidence of PAl has been reported as highest for nivolumab (2.0\%; 95\% Cl 0.9-4.3), followed by ipilimumab (1.4\%; 95\% Cl 0.9-2.2), tremelimumab (1.3\%; 95\% Cl 0.7-2.4), avelumab (1.1\%; $95 \%$ $\mathrm{Cl} 0.3-4.2)$ and pembrolizumab (0.8\%; $95 \% \mathrm{Cl} 0.3-2.0)$. When used in combination, the incidences were much higher, in the range of 5.2\% (95\% Cl 2.9-9.2) for ipilimumab with nivolumab and 7.6\% (95\% Cl 1.2-36.8) for ipilimumab with pembrolizumab. ${ }^{45} \mathrm{ICl}$-related PAl is more common in men than women, and is common in old age (seventh decade of life). The average time of onset for PAI from the initiation of $\mathrm{ICI}$ treatment is 4 months. $^{71}$ The pathophysiology of PAl is unclear; however, it is likely to be an autoimmune activation, as adrenal cortex autoantibodies are detected in patients with ICI-related PAI.
Patients with PAl may present with non-specific symptoms, such as nausea, fatigue, anorexia, abdominal pain, weight loss, dizziness, orthostatic hypotension; and severe PAl cases may develop features of adrenal crisis including hypoglycaemia, hyponatraemia, hyperkalaemia, refractory hypotension, muscle weakness, confusion and, infrequently, hypercalcaemia. All patients with PAl should have imaging to rule out adrenal metastasis and adrenal haemorrhage, before considering ICI-related PAI. Adrenal CT in ICl-related PAI may show evidence of adrenalitis in the form of enlargement of both adrenal glands having relatively smooth borders. ${ }^{72} \mathrm{An}{ }^{18} \mathrm{FDG}$-PET scan may show a transiently high uptake in the adrenal glands in patients with adrenalitis. ${ }^{73}$

Patients with a possible diagnosis of PAl should have blood taken for cortisol and $\mathrm{ACTH}$ before receiving hydrocortisone, if the patient is stable enough. However, blood investigations should not delay the treatment of acutely unwell patients presenting with adrenal crisis. In the setting of a low early-morning cortisol, elevated serum ACTH levels greater than twofold of the upper limit of reference range is in favour of PAl; a normal or suppressed ACTH is in favour of central hypoadrenalism. Early-morning cortisol, when used as a screening test can reduce the number of unnecessary synacthen tests by $21 \%$, as the latter provides no additional information if the early-morning cortisol is $<100 \mathrm{nmol} / \mathrm{L}$ or $>500 \mathrm{nmol} / \mathrm{L}{ }^{74} \mathrm{~A}$ synacthen test will not be able to differentiate PAl from central hypoadrenalism. However, in patients with central hypoadrenalism, the synacthen test will indicate hypoadrenalism only after 3-6 weeks of any pituitary insult, including pituitary surgery, apoplexy or traumatic brain injury. This is the minimal time for adrenal atrophy to occur following ACTH deficiency. ${ }^{75}$

As PAl is associated with mineralocorticoid deficiency, measurement of aldosterone and renin is useful in its diagnosis, which is characterized by low aldosterone and elevated renin levels. If the level of aldosterone that is measured 30 minutes after synacthen injection (along with cortisol) is $<5 \mathrm{ng} / \mathrm{dL}$, it is indicative of mineralocorticoid deficiency. ${ }^{176}$ This test can be used in the diagnosis of an extremely rare, but possible association of PAI and hypophysitis following $\mathrm{ICl}$ therapy. The zona glomerulosa synthesizes aldosterone, primarily under the control of renin and plasma potassium; however, ACTH can stimulate the zona glomerulosa to increase aldosterone secretion. Moreover, the zona glomerulosa usually remains intact in central hypoadrenalism. Hence, post-synacthen test aldosterone levels show an increase in cases with central hypoadrenalism. Adrenal autoantibodies are not routinely recommended in the diagnosis of ICl-related PAI.

The management recommendations for patients with ICl-related PAI, based on CTCAE grades, are given in Table 3. All patients with PAI should be evaluated for possible triggers, including infection. Though hydrocortisone is commonly used in those with severe PAl features, intravenous use of dexamethasone $4 \mathrm{mg}$ is preferred if a diagnosis of PAl is not yet established, and a short synacthen test should be conducted as soon as possible. ${ }^{18}$ All patients with a diagnosis of PAI should be given a medic alert bracelet and education regarding sick-day rules. Patients with PAl and reduced aldosterone levels, refractory orthostatic hypotension, hyponatraemia and hyperkalaemia will benefit from escalating doses of fludrocortisone. ${ }^{76}$

\section{Immune checkpoint-related diabetes mellitus}

ICI-related new-onset insulin-dependent diabetes mellitus (DM) is one of the rarer, but potentially fatal, irAEs. Most cases are secondary to anti-PD-1/PD-L1 monotherapy, though few cases are reported with anti-CTLA-4 monotherapy. ${ }^{45}$ When used as monotherapy, the highest incidence has been reported with nivolumab (2.0\%; $95 \% \mathrm{Cl} 0.7-5.8)$, 
followed by atezolizumab (1.4\%; 95\% Cl 0.2-9.4), avelumab (1.1\%; 95\% Cl 0.2-7.6) and pembrolizumab (0.4\%; 95\% Cl 0.2-1.3).45 The ipilimumab-pembrolizumab combination has an incidence of $2.0 \%$ (95\% $\mathrm{Cl} \mathrm{0.6-5.9).} \mathrm{ICl-related} \mathrm{DM} \mathrm{is} \mathrm{more} \mathrm{common} \mathrm{in} \mathrm{older} \mathrm{men.} \mathrm{It} \mathrm{is}$ characterized by a rapid onset of hyperglycaemia, rapid progression to absolute insulin deficiency and a high risk for diabetic ketoacidosis if not diagnosed and treated early with insulin. More than two-thirds of cases develop diabetic ketoacidosis as the presenting symptom. The onset of ICl-related DM occurs from 1 week to 1 year after initiation of anti-PD-1/PD-L1 therapy. ${ }^{45}$

Due to the rapid progression of hyperglycaemia, these patients have a relatively low glycated haemoglobin $(\mathrm{HbA} 1 \mathrm{C})$ at the time of diagnosis, with a mean level of $7.6 \%$ or $60 \mathrm{mmol} / \mathrm{mol} .{ }^{1}$ Marked hyperglycaemia with normal or only minimally elevated $\mathrm{HbA} 1 \mathrm{C}$ is a common feature in patients with ICl-related DM. The islet cell autoantibodies against glutamic acid decarboxylase, insulinoma-associated antigen-2, insulin and zinc transporter-8 have been detected in only $50 \%$ of cases due to rapid onset beta-cell inflammation. C-peptide levels are low or undetectable in nearly all cases, indicating significant loss of endogenous insulin secretion. ${ }^{1}$ The T Iymphocytes of patients with type 1 DM (T1DM) have a reduced expression of PD-1, PDL-1 and CTLA-4, implying that patients treated with ICIs are susceptible for developing T1DM. Moreover, patients with ICI-related DM shared similar human leukocyte antigen class II genes to those of patients with T1DM. ${ }^{1}$ Apart from new-onset insulin-dependent DM, anti-PD-1 monoclonal antibodies are known to worsen a pre-existing type 2 DM (T2DM).

The diagnosis and management of new-onset insulin-dependent DM use similar established principals to those used for T1DM. The diagnosis can be made during routine testing for hyperglycaemia in an asymptomatic patient on ICI therapy or the patient can present with symptoms of hyperglycaemia (polyuria, polydipsia and weight loss) or with symptoms of diabetic ketoacidosis (nausea, vomiting, abdominal pain, hyperventilation, lethargy, obtundation, seizure or coma). Patients on ICl therapy and their family members should be educated regarding symptoms or hyperglycaemia, as well as diabetic ketoacidosis. The beta-cell destruction is irreversible, hence the insulin requirement is going to be permanent in nearly all patients. Steroids have no role in the management of ICl-related DM. Management of patients with ICl-related DM are given in Table 3.

\section{Primary hypoparathyroidism}

Hypoparathyroidism is an exceedingly rare complication of $\mathrm{ICl}$ therapy, and there are only a handful of case reports showing an association with anti-PD-1 therapy as well as combination therapy, but not with ipilimumab monotherapy. ${ }^{77-79}$ Moreover, hypocalcaemia was observed as a common complication to anti-PD-1 treatment in a recent metaanalysis. ${ }^{77}$ The pathogenic mechanisms for hypoparathyroidism are not established. It might be related to hyperactivation of calcium-sensing receptor (CaSR) of the parathyroid glands by activating CaSR autoantibodies or mediated by an autoimmune destruction of the parathyroid gland triggered by $\mathrm{ICl}$ therapy. Hypoparathyroidism should be considered when hypocalcaemia is associated with low-normal or low parathyroid hormone levels. Anti-parathyroid and CaSR-activating autoantibodies may be detectable in patients with ICI-related hypothyroidism mediated by these autoantibodies. Hypoparathyroidism is largely irreversible and treatment with an activated form of vitamin D along with calcium supplementation are needed on a long-term basis. ${ }^{78}$

\section{Hypogonadotropic hypogonadism}

Transient hypogonadotropic hypogonadism can be seen in patients with hypophysitis. It will manifest as low testosterone levels (in men) or low oestradiol levels (in premenopausal women), associated with low or inappropriately normal FSH and/or LH. In post-menopausal women with typically elevated FSH and $\mathrm{LH}$, inappropriately low FSH and $\mathrm{LH}$ indicate presence of hypogonadotropic hypogonadism. As hyperprolactinaemia is a cause of hypogonadotropic hypogonadism, prolactin levels should be checked in all these patients. However, prolactin levels are low in most cases of hypophysitis, while hyperprolactinaemia is a rare observation. ${ }^{1}$ Hypogonadotropic hypogonadism can develop in the absence of hypophysitis and is especially seen in patients on ipilimumab. ${ }^{80}$ However, it is difficult to interpret the exact aetiology of hypogonadism in this patient population, as the severity of chronic illness (advanced cancer), as well as the high dose systemic corticosteroids that are used for the treatment of various ICl-related non-endocrine irAEs, are known causes of hypogonadotropic hypogonadism.

\section{Diabetes insipidus and syndrome of inappropriate antidiuretic hormone secretion}

Diabetes insipidus is a rare endocrinopathy associated with $\mathrm{ICI}$ therapy, and an extremely rare feature in ICl-related hypophysitis, as this predominantly results in deficiency of anterior pituitary hormones. ${ }^{81}$ The drugs reported to cause diabetes insipidus include ipilimumab, and avelumab. ${ }^{82-84}$ The onset of diabetes insipidus occurs nearly 12 weeks after the initiation of $\mathrm{ICl}$ therapy in these patients. ${ }^{85}$ Another possible association, reported in a couple of case reports, is syndrome of inappropriate antidiuretic hormone secretion (SIADH), manifesting as hyponatraemia. However, both these cases had central hypoadrenalism, which might have caused hyponatraemia, and SIADH had been possibly a wrong diagnosis. ${ }^{86,87}$ Hypoadrenalism results in hyponatraemia by stimulating antidiuretic hormone secretion by various mechanisms that include direct stimulation of antidiuretic hormone release, indirect stimulation of corticotropin-releasing hormone, lowering of blood pressure and cardiac output, and upregulation of the expression of aquaporin-2 in the renal tubules ${ }^{47}$ The resultant rise in antidiuretic hormone levels leads to free water retention and dilutional hyponatraemia.

\section{Adrenocorticotropic hormone-dependent cortisol excess with or without Cushing's syndrome}

Transient ACTH-dependent hypercortisolaemia with or without features of Cushing's syndrome has been reported in two case reports.8.89 Both cases developed central hypoadrenalism on follow-up, indicating the need for close monitoring to detect hypoadrenalism when ACTH elevation is detected in patients on ICI therapy. Transient ACTH elevation can be explained by a destructive hypophysitis analogous to the destructive thyroiditis. ${ }^{88,89}$

\section{Monitoring for endocrinopathies while on immune checkpoint inhibitor therapy}

Patients on $\mathrm{ICl}$ should be routinely monitored for the development of endocrinopathies before each cycle of $\mathrm{ICl}$ therapy (typically every second or third week for the majority of available agents; see Table 1 for further details), every 2-3 months for the next 6 months, and thereafter every 6 months. ${ }^{90}$ Testing should be repeated more frequently if endocrinopathy symptoms develop. Figure 1 illustrates an algorithm for the work-up and management of various ICI-related endocrinopathies. ICI-related clinically significant adrenal insufficiency manifesting with hypotension, dehydration and electrolyte disturbances, whether caused by hypophysitis (central hypoadrenalism) or by PAl, should be treated in 


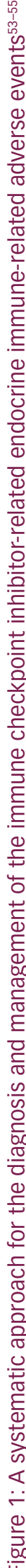
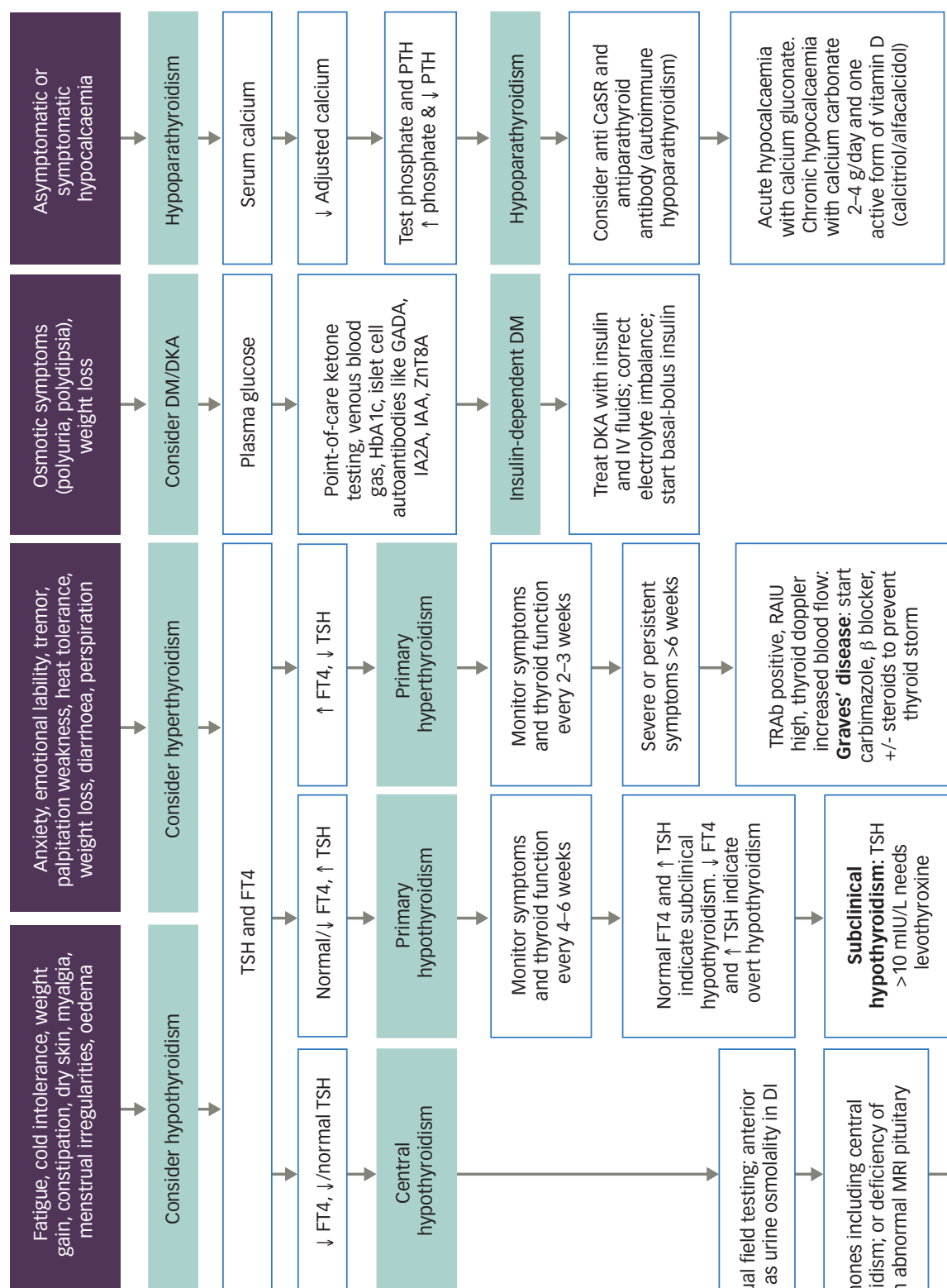

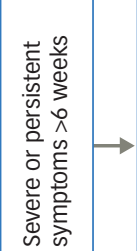
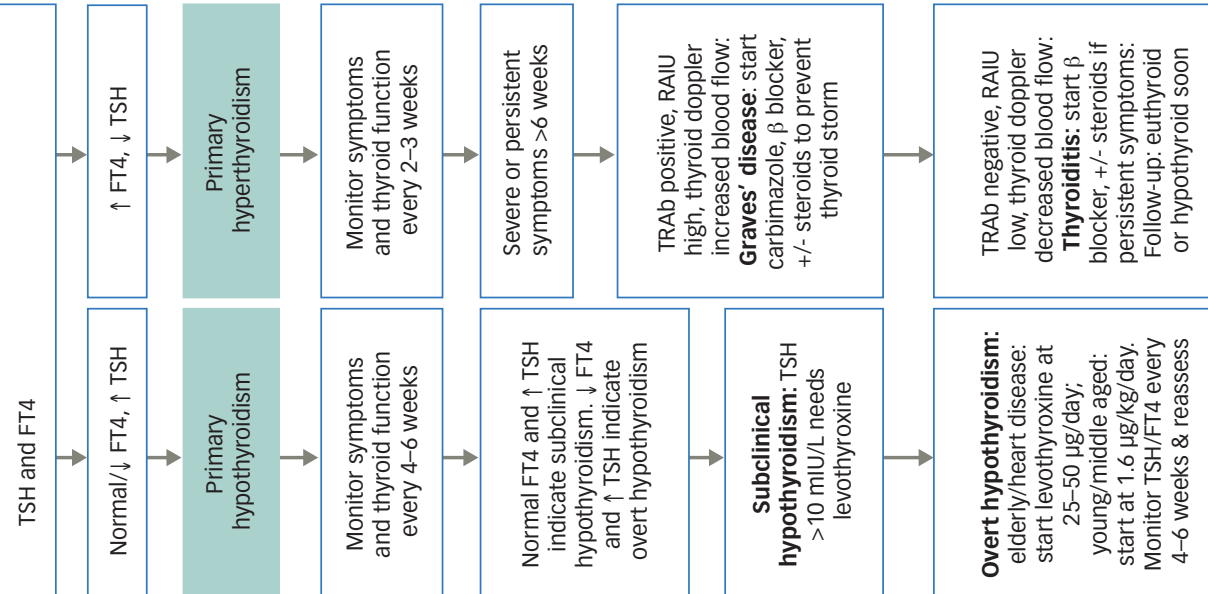

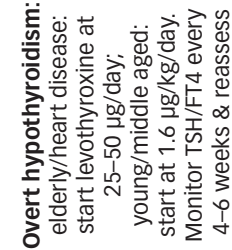
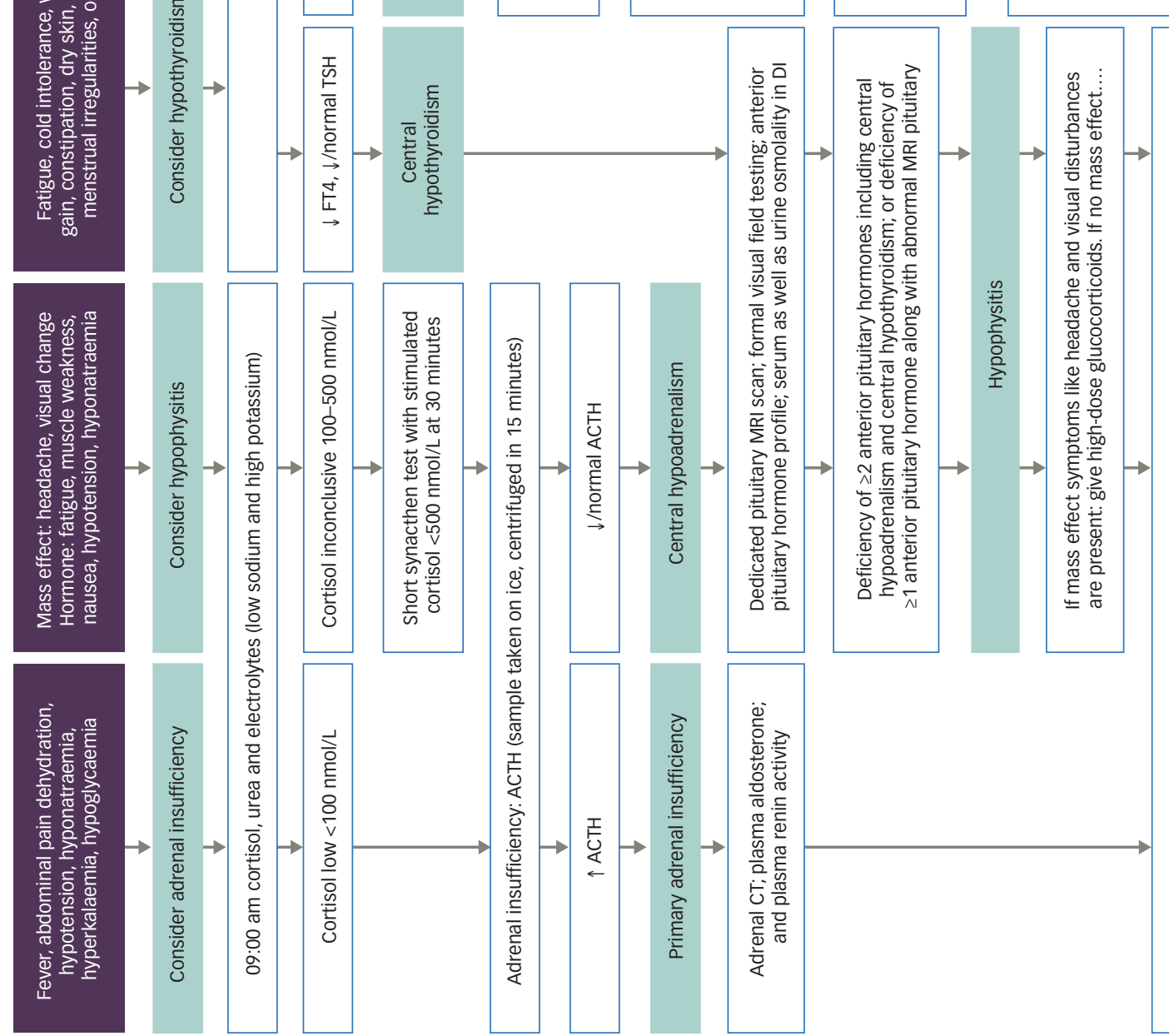

遌高誉

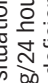

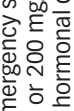

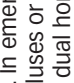

离家高

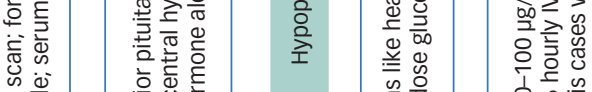

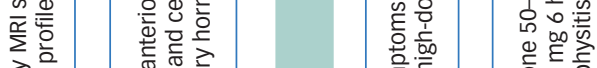

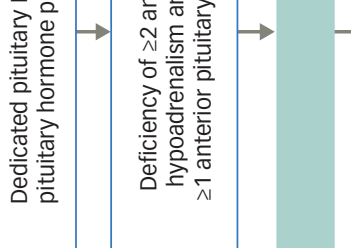

兽㶽 응

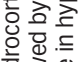

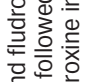

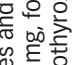

为政

虫

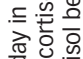

말을 훙

$\stackrel{\sim}{\sim} \geq$

至

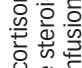

은

소흥 
Figure 2: Percentage incidence of immune checkpoint inhibitor-mediated endocrinopathies with monotherapy and combination therapy ${ }^{45}$

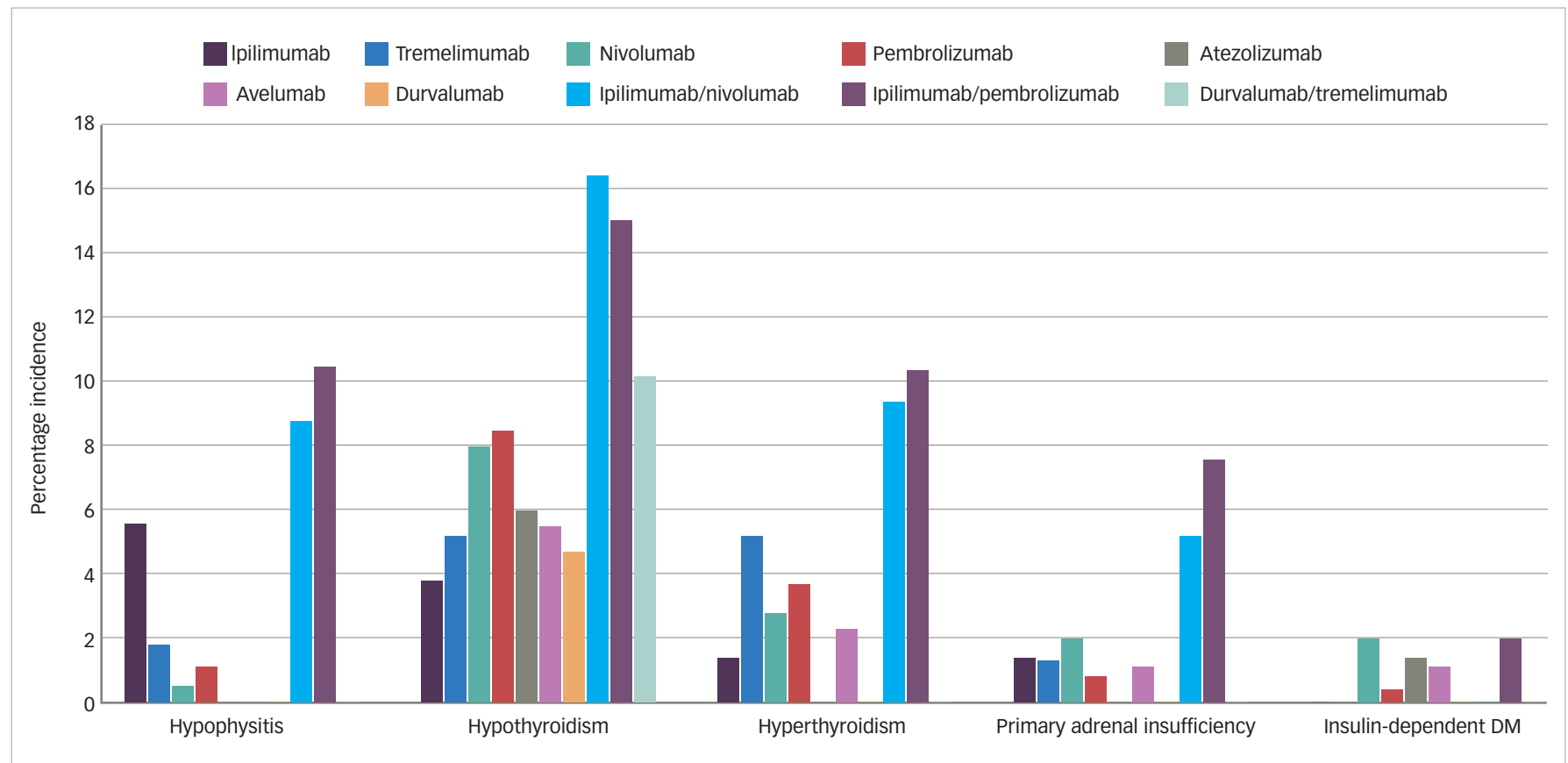

$D M=$ diabetes mellitus

lines of management of adrenal crisis with hospitalization, intravenous hydrocortisone and sepsis work-up. Figure 2 illustrates the percentage incidence of various endocrinopathies (endocrine irAEs) associated with the available monotherapy and combination therapy. From the figure, it is evident that anti-CTLA-4 agents, or their combination, are common causes of hypophysitis. On the other hand, anti-PD-1/PD-L1 agents, or their combination, are a common cause of thyroid dysfunction (hypothyroidism and hyperthyroidism), and the same group can rarely present with PAI and insulin-dependent DM.

\section{Areas of uncertainty}

Patients who have developed irAEs, have been seen to demonstrate superior overall survival and surrogate endpoints, like progression-free survival and recurrence-free survival, in comparison with those who have not developed them. ${ }^{1}$ Activated autoreactive $T$ cells (decreased immune tolerance) mediate the irAEs, and people who develop irAEs have T cells that show better response to ICI therapy. ${ }^{1}$ Hence, their immune system possesses the enhanced ability to destroy the cancer cells (enhanced antitumor activity). Several retrospective observational studies support the hypothesis that endocrine, ${ }^{91-93}$ as well as non-endocrine, ${ }^{94-97}$ irAEs are associated with improved overall survival in ICl-treated patients with various types of cancers.

There is contrasting evidence regarding the severity of irAEs, overall response rate and the time to progression. One study observed improvement in overall response rate (25\% versus $6 \%$ ) and prolongation of median time to progression (30 weeks versus 10 weeks) in patients with high-grade (grade 3-5) irAEs compared with patients without high-grade irAES, respectively. ${ }^{98}$ In contrast, another study observed that those with low-grade (grade 1 or 2) irAEs have higher overall response rate and prolongation of time to next therapy or death.99 The latter observation might be due to the higher morbidity associated with severe irAEs and the requirement for immunosuppressants in the management of these high-grade irAEs. ${ }^{100}$ Thus, a definite conclusion cannot be reached regarding the severity of irAEs and the overall outcome of $\mathrm{ICl}$ therapy until new large prospective trial data are available.

For many years it was considered that irAEs are the necessary price for the cancer immunity that ICIS provide. However, researchers are now trying to uncouple ICI-mediated antitumour activity from ICI-mediated irAEs. One way of doing this is by developing monoclonal antibodies that have dual specificity to both ligands (for example PD-L1) and immune checkpoint receptors (e.g. LAG3 or TIM-3), which are upregulated by tumour cells. ${ }^{101}$ As these monoclonal antibodies with dual specificity can be retained in the tumour microenvironment, sparing the normal tissues, they promote antitumour effects without causing irAEs. ${ }^{102}$ Another way to uncouple the antitumour activity from irAEs is by selective depletion of regulatory $\mathrm{T}$ cells in the tumour microenvironment with the help of pH-sensitive anti-CTLA-4 antibodies that do not result in CTLA-4 depletion in normal tissues. ${ }^{103}$

A third approach under investigation for uncoupling irAEs from the antitumour effects is known as Probody ${ }^{\circledR}$ therapeutics (CytomX Therapeutics, South San Francisco, CA, USA), which is characterized by the development of recombinant, proteolytically activated antibody prodrugs that will become active only when they get exposed to tumour-associated proteases in the tumour microenvironment. ${ }^{104}$ Conjugating $\mathrm{ICl}$ with matrix-binding peptides and then injecting them into or around the tumour may facilitate intra-tumoural retention with lower systemic antibody levels and lower rates of irAEs. ${ }^{105}$

\section{Conclusions}

$\mathrm{ICl}$ therapy is associated with endocrine and non-endocrine irAEs. Thyroid dysfunction and hypophysitis are the most common endocrinopathies, whereas PAI, insulin-dependent DM and hypoparathyroidism are the uncommon members of the group. Anti-CTLA-4 agents are more toxic compared with anti-PD-1/PD-L1 agents, as they are associated with significantly higher numbers 
of irAEs. Hypophysitis is more common with anti-CTLA-4 agents, whereas thyroid dysfunction, insulin-dependent DM and PAI are more common with anti-PD-1/PD-L1 agents. ICl-induced endocrinopathies are potentially fatal if not diagnosed and treated promptly. ICI-related adrenal insufficiency is mostly irreversible, and the replacement therapy often permanent. In contrast, thyroid and gonadal hormonal deficiency may be reversible. Counselling the patient and family members before
$\mathrm{ICI}$ initiation regarding potential irAEs will facilitate early diagnosis of endocrinopathies. Finally, effective co-ordination between oncology and endocrinology departments can improve the outcome of patients with ICl-related endocrinopathies as, in contrast to other irAEs, patients with even high grades of endocrine irAEs can continue their ICI therapy, provided the hormone replacement therapy is adequate and the symptoms are controlled.
1. Chang $L S$, Barroso-Sousa R, Tolaney SM, et al. Endocrine toxicity of cancer immunotherapy targeting immune checkpoints. Endocr Rev. 2019;40:17-65.

2. Pardoll DM. The blockade of immune checkpoints in cancer immunotherapy. Nat Rev Cancer. 2012;12:252-64.

3. Vaddepally RK, Kharel P, Pandey R, et al. Review of indications of FDA-approved immune checkpoint inhibitors per NCCN guidelines with the level of evidence. Cancers (Base). 2020;12:738

4. Kaminska-Winciorek G, Cybulska-Stopa B, Lugowska I, et al. Principles of prophylactic and therapeutic management of skin toxicity during treatment with checkpoint inhibitors. Postepy Dermatol Alergol. 2019:36:382-91.

5. Belum VR, Benhuri B, Postow MA, et al. Characterisation and management of dermatologic adverse events to agents targeting the PD-1 receptor Eur I Cancer 2016:60:12-25.

6. Curry JL, Tetzlaff MT, Nagarajan P, et al. Diverse types of dermatologic toxicities from immune checkpoint blockade therapy. J Cutan Pathol. 2017;44:158-76.

7. Haanen JBAG, Carbonnel F, Robert C, et al. Management of toxicities from immunotherapy: ESMO Clinical Practice Guidelines for diagnosis, treatment, and follow-up. Ann Oncol. 2017;28:iv119-42.

8. Weber JS, Kahler KC, Hauschild A. Management of immune-related adverse events and kinetics of response with ipilimumab. I Clin Oncol. 2012;30:2691-7

9. Hua C, Boussemart L, Mateus C, et al. Association of vitiligo with tumor response in patients with metastatic melanoma treated with pembrolizumab. JAMA Dermatol. 2016; 152:45-51.

10. Hassel JC, Heinzerling L, Aberle J, et al. Combined immune checkpoint blockade (anti-PD-1/anti-CTLA-4): evaluation and management of adverse drug reactions. Cancer Treat Rev. 2017;57:36-49.

11. Kumar V, Chaudhary N, Garg M, et al. Current diagnosis, and management of immune related adverse events (irAES) induced by immune checkpoint inhibitor therapy. Front Pharmacol. 2017;8:49.

12. Spiers L, Coupe $N$, Payne M. Toxicities associated with checkpoint inhibitors-an overview. Rheumatology (Oxford). 2019;58:vii7-16

13. Weber J, Thompson JA, Hamid O, et al. A randomized, double-blind, placebo-controlled, phase II study comparing the tolerability and efficacy of ipilimumab administered with or without prophylactic budesonide in patients with unresectable stage III or IV melanoma. Clin Cancer Res. 2009;15:5591-8.

14. Ascierto PA, Del Vecchio M, Robert C, et al. Ipilimumab $10 \mathrm{mg} / \mathrm{kg}$ versus ipilimumab $3 \mathrm{mg} / \mathrm{kg}$ in patients with unresectable or metastatic melanoma: a randomised, double-blind, multicentre, phase 3 trial. Lancet Oncol. 2017;18:611-22

15. Gonzalez RS, Salaria SN, Bohannon CD, et al. PDinhibitor gastroenterocolitis: case series and appraisal of "immunomodulatory gastroenterocolitis". Histopathology. 2017;70:558-67.

16. Cramer P, Bresalier RS. Gastrointestinal and hepatic complications of immune checkpoint inhibitors Curr Gastroenterol Rep. 2017;19:3.

17. Karamchandani DM, Chetty R. Immune checkpoint inhibitor-induced gastrointestinal and hepatic injury: pathologists' perspective. I Clin Pathol. 2018:71:665-71.

18. Brahmer JR, Lacchetti C, Schneider BJ, et al. Management of immune-related adverse events in patients treated with immune check point inhibitor therapy: American Society of Clinical Oncology Clinical Practice Guideline. J Clin Oncol. 2018;36:1714-68

19. Abu-Sbeih H, Ali FS, Wang X, et al. Early introduction of selective immunosuppressive therapy associated with favourable clinica outcomes in patients with immune checkpoint inhibitor-induced colitis. J Immunother Cancer. 2019;7:93.

20. Bergqvist V, Hertervig E, Gedeon P, et al. Vedolizumab treatment for immune checkpoint inhibitor-induced enterocolitis. Cancer Immunol Immunother. 2017;66:581-92.

21. Wang $Y$, Wiesnoski DH, Helmink BA, et al. Faecal microbiota transplantation for refractory immune checkpoint inhibitor-associated colitis. Nat Med. 2018:24:1804-8.

22. Baraibar I, Melero I, Ponz-Sarvise $M$, et al. Safety and tolerability of immune checkpoint inhibitors (PD-1 and PD-L1) in cancer. Drug Saf. 2019;42:281-94.

23. Da $L$, Teng $Y$, Wang $N$, et al. Organ-specific immune-related adverse events associated with immune checkpoint inhibito monotherapy versus combination therapy in cancer: a meta-analysis of randomized controlled trials. Front Pharmacol. 2020;10:1671

24. Shannon VR. Pneumotoxicity associated with immune checkpoint inhibitor therapies. Curr Opin Pulm Med. 2017;23:305-16.

25. Fessas P, Possamai LA, Clark J, et al. Immunotoxicity from checkpoint inhibitor therapy: clinical features and underlying mechanisms. Immunology. 2020;159:167-77.
26. Black JR, Goldin RD, Foxton M, et al. PD-L1 expressing granulomatous reaction as an on-target mechanism of steroid-refractory immune hepatotoxicity. Immunotherapy. 2019;11:585-90.

27. Zen Y, Yeh MM. Hepatotoxicity of immune checkpoint inhibitors: a histology study of seven cases in comparison with autoimmune hepatitis and idiosyncratic drug-induced liver injury. Mod Pathol. 2018;31:965-73.

28. Johncilla M, Misdraji J, Pratt DS, et al. Ipilimumab associated hepatitis: clinicopathologic characterization in a series of 11 cases. Am I Surg Pathol. 2015;39:1075-84.

29. De Martin E, Michot JM, Papouin B, et al. Characterization of liver injury induced by cancer immunotherapy using immune checkpoint inhibitors. J Hepatol. 2018:68:1181-90.

30. Champiat S, Lambotte O, Barreau E, et al. Management of immune checkpoint blockade dysimmune toxicities: A collaborative position paper. Ann Oncol. 2016;27:559-74.

31. Herrmann SM, Perazella MA. Immune checkpoint inhibitors and immune-related adverse renal events. Kidney Int Rep. 2020;5:1139-48

32. Perazella MA, Shirali AC. Immune checkpoint inhibitor nephrotoxicity: what do we know and what should we do? Kidney Int. 2020;97:62-74.

33. Dal'bo N, Patel R, Parikh R, et al. Cardiotoxicity of contemporary anticancer immunotherapy. Curr Treat Options Cardiovasc Med. 2020:22:62.

34. Mahmood SS, Fradley MG, Cohen JV, et al. Myocarditis in patients treated with immune checkpoint inhibitors. J Am patients treated with immune
Coll Cardiol. 2018:71:1755-64.

35. Ganatra S, Parikh R, Neilan TG. Cardiotoxicity of immune therapy Cardiol Clin. 2019:37:385-97.

36. Abdel-Wahab N, Suarez-Almazor ME. Frequency and distribution of various rheumatic disorders associated with checkpoint inhibitor therapy. Rheumatology (Oxford). 2019;58:vii40-8

37. Melissaropoulos K, Klavdianou K, Filippopoulou A, et al. Rheumatic manifestations in patients treated with immune checkpoint inhibitors. Int J Mol Sci. 2020;21:3389.

38. Puzanov I, Diab A, Abdallah K, et al. Managing toxicities associated with immune checkpoint inhibitors: consensus recommendations from the Society for Immunotherapy of Cancer (SITC) Toxicity Management Working Group. J Immunother Cancer. 2017:5:95.

39. Pan PC, Haggiagi A. Neurologic immune-related adverse events associated with immune checkpoint inhibition. Curr Oncol Rep. 2019;21:108.

40. Vilarino N, Bruna J, Kalofonou F, et al. Immune-driven pathogenesis of neurotoxicity after exposure of cancer patients to immune checkpoint inhibitors. Int J Mol Sci. 2020;21:5774.

41. Harrison RA, Tummala S, de Groot J. Neurologic toxicities of cancer immunotherapies: a review. Curr Neurol Neurosci Rep. 2020;20:27.

42. Douglas VP, Douglas KAA, Cestari DM. Immune checkpoint inhibitors: what neuro-ophthalmologists need to know. Curr Opin Ophthalmol. 2019;30:426-33.

43. Dalvin LA, Shields $\mathrm{CL}$, Orloff $\mathrm{M}$, et al. Checkpoint inhibitor immune therapy: systemic indications and ophthalmic side effects. Retina. 2018;38:1063-78.

44. Omar NE, El-Fass KA, Abushouk Al, et al. Diagnosis and management of hematological adverse events induced by immune checkpoint inhibitors: a systematic review. Front Immunol. 2020:11:1354.

45. de Filette J, Andreescu CE, Cools F, et al. A systematic review and meta-analysis of endocrine-related adverse events associated with immune checkpoint inhibitors. Horm Metab Res. 2019;51:145-56.

46. Faje AT, Sullivan R, Lawrence D, et al. Ipilimumab-induced hypophysitis: a detailed longitudinal analysis in a large cohort of patients with metastatic melanoma. J Clin Endocrinol Metab. 2014;99:4078-85

47. Di Dalmazi G, Ippolito S, Lupi I, et al. Hypophysitis induced by immune checkpoint inhibitors: a 10-year assessment Expert Rev Endocrinol Metab. 2019;14:381-98.

48. Iwama S, De Remigis A, Callahan MK, et al. Pituitary expression of CTLA-4 mediates hypophysitis secondary to administration A-4 blocking antibody SciTrans/ Med

49. Faje A. Immunotherapy and hypophysitis: clinical presentation, treatment and biologic insights. Pituitary. 2016:19:82-92.

50. Caturegli P, Di Dalmazi G, Lombardi M, et al. Hypophysitis secondary to cytotoxic T-lymphocyte-associated protein 4 blockade: insights into pathogenesis from an autopsy series. Am J Pathol. 2016;186:3225-35.

51. Caturegli $P$, Newschaffer $C$, Olivi A, et al. Autoimmune hypophysitis. Endocr Rev. 2005;26:599-614

52. Ryder M, Callahan M, Postow MA, et al. Endocrine-related adverse events following ipilimumab in patients with advanced melanoma: a comprehensive retrospective review from a single institution. Endocr Relat Cancer. 2014;21:371-81.

53. Wallace I, Cunningham S, Lindsay J. The diagnosis and investigation of adrenal insufficiency in adults. Ann Clin Biochem. 2009;46:351-67.

54. Struja T, Briner L, Meier A, et al. Diagnostic accuracy of basal cortisol level to predict adrenal insufficiency in cosyntropin testing: results from an observational cohort study with 804 patients. Endocr Pract. 2017;23:949-61.

55. Mongioi LM, Condorelli RA, Barbagallo F, et al. Accuracy of the low-dose ACTH stimulation test for adrenal insufficiency diagnosis: a re-assessment of the cut-off value. J Clin Med. 2019;8:806.

56. National Cancer Institute DCTD (Division of Cancer Treatment and Diagnosis) Cancer Therapy Evaluation Program, Common terminology criteria for adverse events (CTCAE) Version 5.0, 2017. Available at: https://ctep.cancer.gov/ version 5.0, 2017. Available at. https.//ctep.cancer.gov/ protocolDevelopment/electronic_applications/docs/CTCAE-

57. MCMillen B, Dhillon MS, Yong-Yow S. A rare case of thyroid storm. BMJ Case Reports. 2016;2016:bcr2016214603.

58. Morganstein DL, Lai Z, Spain L, et al. Thyroid abnormalities following the use of cytotoxic T-lymphocyte antigen- 4 and programmed death receptor protein-1 inhibitors in the treatment of melanoma. Clin Endocrinol (OXf). 2017;86:614-20,

59. Alhusseini M, Samantray J. Hypothyroidism in cancer patients on immune checkpoint inhibitors with anti-pd1 agents: insights on underlying mechanisms. Exp Clin Endocrinol Diabetes. 2017;125:267-9.

60. Azmat U, Liebner D, Joehlin-Price A, et al. Treatment of ipilimumab induced Graves' disease in a patient with metastatic melanoma. Case Rep Endocrinol. 2016:2016:2087525.

61. Gan EH, Mitchell AL, Plummer R, et al. Tremelimumab-induced Graves hyperthyroidism. Eur Thyroid J. 2017;6:167-70.

62. Andersen TB, Aleksyniene R, Gormsen LC, et al. Effect of recent contrast-enhanced CT and patient age on image quality of thyroid scintigraphy. Clin NuCl Med. 2015;40:297-302.

63. Lee SY, Rhee CM, Leung AM, et al. A review: radiographic iodinated contrast media-induced thyroid dysfunction. J Clin Endocrinol Metab. 2015;100:376-83.

64. Yamauchi I, Sakane Y, Fukuda Y, et al. Clinical features of nivolumab-induced thyroiditis: a case series study. Thyroid. 2017;27:894-901

65. Kobayashi T, Iwama S, Yasuda Y, et al. Patients with antithyroid antibodies are prone to develop destructive thyroiditis by nivolumab: a prospective study. J Endocr Soc. 2018:2:241-51.

66. Neppl C, Kaderli RM, Trepp R, et al. Histology of nivolumab-induced thyroiditis. Thyroid. 2018:28:1727-8.

67. Angell TE, Min L, Wieczorek TJ, et al. Unique cytologic features of thyroiditis caused by immune checkpoint inhibitor therapy for malignant melanoma. Genes Dis. 2018:5:46-8.

68. Ribas A, Kefford R, Marshall MA, et al. Phase III randomized clinical trial comparing tremelimumab with standard-of-care chemotherapy in patients with advanced melanoma. J Clin Oncol. 2013;31:616-22.

69. Brancatella A, Viola N, Brogioni S, et al. Graves' disease induced by immune checkpoint inhibitors: a case report and review of the literature. Eur Thyroid J. 2019;8:192-5.

70. Meeran K. Optimising glucocorticoid replacement in adrenal insufficiency. Br J Diabetes. 2019;19:131-2.

71. Grouthier V, Lebrun-Vignes B, Moey M, et al. immune checkpoint inhibitor-associated primary adrenal insufficiency: WHO VigiBase report analysis. Oncologist. 2020:25:696-701.

72. Paepegaey AC, Lheure $C$, Ratour $C$, et al. Polyendocrinopathy resulting from pembrolizumab in a patient with a malignant melanoma. J Endocr Soc. 2017;1:646-9.

73. Min L, Ibrahim N. Ipilimumab-induced autoimmune adrenalitis. Lancet Diabetes Endocrinol. 2013;1:e15.

74. Le Roux CW, Meeran K, Alaghband-Zadeh J. Is a 0900-h serum cortisol useful prior to a short synacthen test in outpatient assessment? Ann Clin Biochem. 2002;39:148-50.

75. Crowley RK, Argese N, Tomlinson JW, et al. Centra hypoadrenalism. J Clin Endocrinol Metab. 2014;99:4027-36.

76. Salinas C, Renner A, Rojas C, et al. Primary adrenal insufficiency during immune checkpoint inhibitor treatment: case reports and review of the literature. Case Rep Oncol. 2020;13:621-6.

77. El Kawkgi OM, Li D, Kotwal A, et al. Hypoparathyroidism: an uncommon complication associated with immune checkpoin incommon complication associated with immune chec 2020;: $: 821-5$.

78. Trinh B, Sanchez GO, Herzig P, et al. Inflammation-induced hypoparathyroidism triggered by combination immune checkpoint blockade for melanoma. J Immunother Cancer. 2019;7:52.

79. Dadu R, Rodgers TE, Trinh VA, et al. Calcium-sensing receptor autoantibody-mediated hypoparathyroidism associated with immune checkpoint inhibitor therapy: diagnosis and long-term follow-up. I Immunother Cancer. 2020;8:e000687.

80. Manohar S, Kompotiatis P, Thongprayoon C, et al. Programmed cell death protein 1 inhibitor treatment is associated with acute kidney injury and hypocalcemia: meta-analysis. Nephrol Dial Transplant. 2019;34:108-17. 
81. Bai $X$, Lin $X$, Zheng $K$, et al. Mapping endocrine toxicity spectrum of immune checkpoint inhibitors: a disproportionality analysis using the WHO adverse drug reaction database, VigiBase. Endocrine. 2020;69:670-81.

82. Dillard T, Yedinak CG, Alumkal I, et al. Anti-CTLA-4 antibody therapy associated autoimmune hypophysitis: serious immune related adverse events across a spectrum of cancer subtypes. Pituitary. 2010;13:29-38.

83. Nallapaneni NN, Mourya R, Bhatt VR, et al. Ipilimumab-induced hypophysitis and uveitis in a patient with metastatic melanoma and a history of ipilimumab-induced skin rash. J Nat/ Compr Canc Netw. 2014;12:1077-81.

84. Zhao C, Tella SH, Del Rivero J, et al. Anti-PD-L1 treatment induced central diabetes insipidus. I Clin Endocrinol Metab. 2018;103:365-9.

85. Tan MH, lyengar R, Mizokami-Stout K, et al. Spectrum of immune checkpoint inhibitors-induced endocrinopathies in cancer patients. a scoping review of case reports. Clin Diabetes Endocrinol. 2019:5:1.

86. Barnard ZR, Walcott BP, Kahle KT, et al. Hyponatremis associated with Ipilimumab-induced hypophysitis. Med Oncol. 2012:29:374-7.

87. Trainer $\mathrm{H}$, Hulse $\mathrm{P}$, Higham $\mathrm{CE}$, et al. Hyponatraemia secondary to nivolumab-induced primary adrenal failure. Endocrinol Diabetes Metab Case Rep. 2016;2016:16-0108

88. Lupu J, Pages C, Laly P, et al. Transient pituitary ACTH-dependent Cushing syndrome caused by an immune checkpoint inhibitor combination. Melanoma Res. 2017;27:649-52

89. Sekizaki T, Kameda H, Oba C, et al. Nivolumab-induced hypophysitis causing secondary adrenal insufficiency after transient ACTH elevation. Endocr J. 2019:66:937-41.
90. Castinetti F, Albarel F, Archambeaud F, et al. French Endocrine Society Guidance on endocrine side effects of immunotherapy. Endocr Relat Cancer. 2019:26:G1-G18.

91. Yamauchi I, Yasoda A, Matsumoto S, et al. Incidence features, and prognosis of immune-related adverse events involving the thyroid gland induced by nivolumab. PLOS One. 2019;14: 0216954

92. Osorio JC, Ni A, Chaft JE, et al. Antibody-mediated thyroid dysfunction during T-cell checkpoint blockade in patients with non-small-cell lung cancer. Ann Oncol. 2017;28:583-9.

93. Rogado J, Sanchez-Torres JM, Romero-Laorden N, et al. Immune-related adverse events predict the therapeutic efficacy of anti-PD-1 antibodies in cancer patients. Eur I Cancer. 2019;109:21-7.

94. Indini A, Di Guardo L, Cimminiello C, et al. Immune-related adverse events correlate with improved survival in patients undergoing anti-PD1 immunotherapy for metastatic melanom J Cancer Res Clin Oncol. 2019;145:511-21.

95. Eggermont $\mathrm{AMM}$, Kicinski $\mathrm{M}$, Blank $\mathrm{CU}$, et al. Association between immune-related adverse events and recurrence-free survival among patients with stage II melanoma randomized to receive pembrolizumab or placebo: a secondary analysis of a randomized clinical trial. placebo: a secondary analysis
JAMA Oncol. 2020;6:519-27.

96. Hosoya K, Fujimoto D, Morimoto T, et al. Association between early immune-related adverse events and clinical outcomes in patients with non-small cell lung cancer treated with immune checkpoint inhibitors. Clin Lung Cancer. 2020;21:e315-28.

97. Masuda K, Shoji H, Nagashima K, et al. Correlation between immune-related adverse events and prognosis in patients with gastric cancer treated with nivolumab. BMC Cancer. 2019;19:974.

98. Fujii T, Colen RR, Bilen MA et al. Incidence of immune-related adverse events and its association with treatment outcomes: the MD Anderson Cancer Center experience. Invest New Drugs. 2018;36:638-46.

99. Judd J, Zibelman $M$, Handorf $E$, et al. Immune-related adverse events as a biomarker in non-melanoma patients treated with programmed cell death 1 inhibitors. Oncologist. 2017;22:1232-7

100. Quach HT, Dewan AK, Davis EJ, et al. Association of anti-programmed cell death 1 cutaneous toxic effects with outcomes in patients with advanced melanoma. JAMA Oncol. 2019;5:906-8.

101. Dahlen E, Veitonmaki N, Norlen P. Bispecific antibodies in cancer imm $2018: 6: 3-17$.

102. Hu W, Wang G, Wang Y, et al. Uncoupling therapeutic efficacy from immune-related adverse events in immune checkpoint blockade. iscience. 2020;23:101580.

103. Zhang Y, Du X, Liu M, et al. Hijacking antibody-induced CTLA-4 lysosomal degradation for safer and more effective cancer lysosomal degradation for safer and more
immunotherapy. Cell Res. 2019;29:609-27.

104. Autio KA, Boni V, Humphrey RW, et al. Probody therapeutics: an emerging class of therapies designed to enhance on-target effects with reduced off-tumor toxicity for use in immuno-oncology. Clin Cancer Res. 2020;26:984-9.

105. Ishihara J, Fukunaga K, Ishihara A, et al. Matrix-binding checkpoint immunotherapies enhance antitumor efficacy and reduce adverse events. Sci Trans/ Med. 2017:9:eaan0401. 